\title{
The Physiology of Apology: An Investigation into Potential Sex Differences
}

\author{
Daniel Stephenson
}

Follow this and additional works at: https://researchrepository.wvu.edu/etd

\section{Recommended Citation}

Stephenson, Daniel, "The Physiology of Apology: An Investigation into Potential Sex Differences" (2016). Graduate Theses, Dissertations, and Problem Reports. 6721.

https://researchrepository.wvu.edu/etd/6721

This Thesis is protected by copyright and/or related rights. It has been brought to you by the The Research Repository @ WVU with permission from the rights-holder(s). You are free to use this Thesis in any way that is permitted by the copyright and related rights legislation that applies to your use. For other uses you must obtain permission from the rights-holder(s) directly, unless additional rights are indicated by a Creative Commons license in the record and/ or on the work itself. This Thesis has been accepted for inclusion in WVU Graduate Theses, Dissertations, and Problem Reports collection by an authorized administrator of The Research Repository @ WVU. For more information, please contact researchrepository@mail.wvu.edu. 
The Physiology of Apology:

An Investigation into Potential Sex Differences

Daniel Stephenson

Thesis submitted

to the Eberly College of Arts and Sciences

at West Virginia University

in partial fulfillment of the requirements for the degree of

Master of Science in Psychology

Kevin T. Larkin, Ph.D. - Chair

Daniel W. McNeil, Ph.D.

Julie Hicks Patrick, Ph.D.

Department of Psychology

Morgantown, West Virginia

2016

Keywords: forgiveness, apology, sex differences, cardiovascular reactivity, heart rate variability

Copyright 2016 Daniel Stephenson 


\section{ABSTRACT \\ The Physiology of Apology: \\ An Investigation into Potential Sex Differences \\ Daniel Stephenson}

Current literature on apology indicates that men and women differ in the types of apologies they offer and accept. In a recent study, Whited, Wheat, and Larkin (2010) showed that males and females may also experience differing physiological benefits following an apology. The purpose of the current study was to replicate the experimental study by Whited et al. and extend it by examining two different types of apologies. This study employed a 2 (men, women) X 3 (elaborate apology, simple apology, no apology) between subjects design to determine whether sex of participant and type of apology influenced the rate of cardiovascular and affective recovery from a standard experimental transgression. Seventy-Seven participants performed a mental arithmetic task during which they were verbally harassed by the experimenter. Following the task/verbal harassment, participants received either an elaborate apology, a simple apology, or no apology from the experimenter, followed by a 10-minute recovery period. Blood pressure [systolic (SBP), diastolic (DBP), mean arterial (MAP)], heart rate (HR), and heart rate variability (HF-HRV) were measured throughout the experiment. Findings indicated that participant sex and type of apology did not influence SBP, DBP, MAP, or HR recovery. However, a significant type of apology by sex of participant interaction was detected for a measure of parasympathetic nervous system recovery, HF-HRV. Women randomized to the elaborate apology condition recovered more quickly than women in the simple apology condition, and men in the simple apology condition recovered more quickly than women in the simple apology condition. Although findings failed to replicate the work of Whited et al., new clues were discovered regarding how men and women respond to different types of apologies. 


\section{TABLE OF CONTENTS}

Introduction $\quad 1$

Defining Forgiveness 3

Forgiveness and Health $\quad 4$

$\begin{array}{ll}\text { The Physiology of Forgiveness } & 7\end{array}$

$\begin{array}{lr}\text { Apology and Forgiveness } & 8\end{array}$

Sex Differences in Responses to Apology 11

$\begin{array}{ll}\text { Aims of Proposed Study } & 14\end{array}$

$\begin{array}{ll}\text { Method } & 15\end{array}$

$\begin{array}{ll}\text { Participants } & 15\end{array}$

$\begin{array}{ll}\text { Measures } & 16\end{array}$

$\begin{array}{ll}\text { Experimental Design } & 18\end{array}$

$\begin{array}{ll}\text { Procedure } & 19\end{array}$

$\begin{array}{ll}\text { Results } & 19\end{array}$

Data Cleaning and Reduction $\quad 22$

Cardiovascular Measures at Rest 25

Cardiovascular Reactivity to the Task 26

$\begin{array}{ll}\text { Cardiovascular Recovery } & 27\end{array}$

$\begin{array}{ll}\text { Measures of Affect } & 29\end{array}$

Post-Experimental Questionnaire 32

Forgiving Personality and Rumination 33

$\begin{array}{ll}\text { Discussion } & 34\end{array}$

Cardiovascular Recovery Following Apology 35

Affective Response and Recovery from Stress $\quad 40$ 
Post-Experimental Questionnaire $\quad 42$

Limitations of the Study $\quad 43$

$\begin{array}{ll}\text { Conclusions } & 45\end{array}$

$\begin{array}{ll}\text { References } & 47\end{array}$

$\begin{array}{ll}\text { Tables } & 58\end{array}$

$\begin{array}{ll}\text { Figures } & 63\end{array}$

$\begin{array}{lr}\text { Appendices } & 69\end{array}$ 
The Physiology of Apology:

\section{An Investigation into Potential Sex Differences}

Every year, approximately 600,000 people in the United States die of cardiovascular disease, one in every four deaths, costing an estimated $\$ 108.9$ billion annually (Center for Disease Control and Prevention, 2014). It is well established that certain health behaviors increase the risk of cardiovascular disease, including consuming high fat, low fiber diets, living sedentary lifestyles, and smoking (Honjo et al., 2010; Katcher et al., 2008; Staiano, Harrington, Barreira, \& Katzmarzyk, 2013). Health behaviors account for a large portion of the variance in explaining who will develop cardiovascular disease, but a significant number of people who eat healthy diets, don’t smoke, and are relatively active still develop cardiovascular disease.

Over the past several decades, evidence has been accruing that a range of psychosocial factors play a significant role in the development of cardiovascular disease. In 1999, Rozanski, Blumenthal, and Kaplan (1999) published a review of studies that examined psychosocial factors and the development of coronary artery disease (CAD), a major type of cardiovascular disease in which the disease process occurs in the coronary arteries leading to ischemia (restricted blood flow) and/or infarction (total lack of blood flow) of the heart. Their review uncovered evidence to suggest that depression, anxiety, social isolation, chronic life stress, and personality traits (especially hostility) each contributed to the development of CAD both through behavioral mechanisms and direct pathophysiological mechanisms (Rozanski et al., 1999). Subsequent studies have confirmed findings that these psychosocial parameters are associated with increased risk for CAD (e.g., Guerrero \& Palmero, 2010; Holt, et al., 2013; Low, Salomon, \& Matthews, 2009; Rugulies, 2002; Wang, Mittleman, Leineweber, \& Orth-Gomer, 2006; Wulsin \& Singal, 2003). 
Although engagement in poor health behaviors and experiencing negative psychosocial factors play a significant role in predicting risk for CAD, they do not explain the development of heart disease completely. Many people who adopt healthy lifestyle habits and have low levels of negative psychosocial factors still develop heart disease. Consequently, scientists interested in acquiring a comprehensive understanding of all behavioral risk factors for CAD continue to explore additional psychosocial factors that could help explain behavioral risk for CAD more completely.

Recent attention has been given to the effects of positive psychosocial factors on the development and expression of cardiovascular diseases as well as other diseases (e.g., Boehm, Peterson, Kivimaki, \& Kubzansky, 2011; Dubois et al., 2012; Oreskovic \& Goodman, 2013). In contrast to identifying behavioral risk factors associated with the greater experience and exposure to negative affect (e.g., depression, anxiety, stress, hostility), the purpose of this line of inquiry is to examine behavioral risk factors associated with reductions in the experience of positive experiences and emotions. Consideration of social support in the review by Rozanski et al. (1999) represents the initial foray into this line of inquiry. According to this perspective, exposure to positive life events and experiencing positive affect may reduce risk of CAD and other forms of cardiovascular disease. Tindle et al. (2009), for example, found that individuals high in trait optimism were less likely to develop heart disease and die from it than those low in trait optimism, and that this effect was independent from the negative influence of hostility on both incidence of heart disease and mortality. Emotional vitality, defined as "a sense of vitality, positive well-being, and emotional control," is another positive psychological construct that has been shown to be associated with a decreased risk of developing heart disease (Low, Thurston, \& Matthews, 2010). Other positive psychosocial factors linked to a decreased risk or reduction of 
symptoms in cardiovascular disease include emotional flexibility (Rozanski \& Kubzansky, 2005), social support (Tay, Tan, Diener, \& Gonzalez, 2013), and forgiveness (Waltman et al., 2009). Although there are many positive psychology parameters that warrant additional scrutiny with respect to gaining a more complete understanding of the behavioral risk factors that predict cardiovascular disease, the proposed project focuses on the phenomenon of forgiveness.

\section{Defining Forgiveness}

Wade and Worthington (2005) defined forgiveness as “a positive method of coping with hurt or offense that primarily benefits the victim through reorientation of thoughts, and/or actions toward the offender” (p.160). Others have defined forgiveness as letting go of resentment and negative judgment of someone who has wronged you, while fostering compassion towards that person (Hart \& Shapiro, 2002). Forgiveness is not, however, tolerating, pardoning, or enduring hurtful behavior (Wade \& Worthington, 2005). One can forgive an offender but still avoid that person as to prevent future personal transgressions.

Unforgiveness is the opposite of forgiveness and includes retaining negative emotions towards the person that wronged you (Worthington, Sandage, \& Berry, 2000). Feelings often associated with unforgiveness are hatred, hostility, resentment, and bitterness. According to Worthington et al. (2000), unforgiveness is typically associated with a prolonged response to a transgression associated with both the experience of the aforementioned emotions, frequent rumination about the transgression, and either holding a grudge or seeking revenge. Although most individuals experience some degree of unforgiveness immediately after a transgression, those who forgive the offender move beyond these initial negative reactions and grudge holding or urges to seek revenge dissipate. For persons who persist in the unforgiving state, years and even decades pass during which grudges are held and motivations to seek revenge persist. 


\section{Forgiveness and Health}

Recognizing that many facets of unforgiveness (e.g., hostility, stress, rumination) have been associated with increased risk for cardiovascular disease, it is only logical that investigators would begin examining the association between forgiveness and health, including cardiovascular health (e.g., Toussaint, Owen, \& Cheadle 2012; Webb, Hirsch, Visser, \& Brewer, 2013). Although the body of literature linking forgiveness with health is not substantial, research suggests that forgiving is associated with lower levels of cardiovascular disease indicators (Friedberg, Suchday, \& Srinivas 2009; Waltman et al., 2009); however, the mechanism by which forgiveness reduces cardiovascular disease risk is unclear. It seems plausible that the mechanism through which forgiveness is associated with lower risk of cardiovascular disease involves the neural interrelations between the brain (where decisions to forgive or not to forgive are presumably made) and the heart and vasculature (where heart disease emerges). Fortunately, there has been a considerable amount of research conducted that has examined the neural connections between the brain and the cardiovascular system, and we know a good bit about how exposure to various psychological and interpersonal stressors influences the cardiovascular system.

Cardiovascular Response to Stress. The primary neural pathways that connect the brain with the heart are the sympathetic and parasympathetic branches of the autonomic nervous system. There are two indirect connections between the brain and heart (and vasculature) as well: the neuroendocrine system, through which the brain regulates stress hormone secretion, and the immune system, that is also regulated by the cortex. It is important to note that these three systems interact with one another, such that increased activity in one of them prompts activation of all three. Typically, the autonomic responses to any type of psychological or interpersonal 
stress occur more quickly than the neuroendocrine and immune system responses, mainly because of the direct neural routes between the brain and the heart through the sympathetic nervous system ganglia and the vagal nerve. In brief, activation of the sympathetic nervous system results in increased heart rate (through $\beta$ adrenergic activity) and increased constriction of the primary arteries (through $\alpha$ adrenergic activity). To prevent drastic elevations in blood pressure due to the simultaneous influence of $\alpha$ and $\beta$ adrenergic responses during exposure to stress, the $\beta$ adrenergic pathway dilates the primary arteries (which can fully or partially offset the vasoconstriction being caused by the $\alpha$ adrenergic branch. The vagal nerve does not innervate the vasculature, but does have a strong influence on heart rate; in contrast to the influence of the sympathetic nervous system, vagal nerve activation results in heart rate deceleration.

It is well established that both sympathetic and parasympathetic branches of the autonomic nervous system are responsive to exposure to stress in both humans and animals (e.g., McEwen \& Stellar, 1993). Not surprisingly, individual differences exist with respect to the magnitude and patterning of the autonomic nervous system response to stress. Given exposure to comparable environmental stressors, some organisms react with relatively small increases in heart rate (HR) and blood pressure (BP) while others react with substantial increases in both HR and BP (Krantz \& Manuck, 1984). Considering risk for cardiovascular disease, there is evidence that the magnitude and pattern of this stress response matters. For example, it has been shown that individuals with greater BP responses to standardized stress presentations are more likely to exhibit cardiovascular disease later in life than those will smaller BP responses to stress (e.g., Carroll et al., 2012; Matthews et al., 2004). Identical findings have been observed among 
macaques (e.g., Manuck, Kaplan, \& Clarkson, 1983); animals with the highest HR reactions to stress showed greater blockage of coronary and carotid arteries than low-reactive animals.

Indeed, multiple studies have demonstrated that cardiovascular response to acute stressors is predictive of future cardiovascular disease. A review by Treiber et al. (2003) examined prospective studies and demonstrated that blood pressure responses during acute stress tasks were predictive of future hypertension and other preclinical states (e.g., increased left ventricular mass) among initially healthy samples, as well as increased number of future clinical events among samples who had already developed cardiovascular disease.

Given that elevated HR or BP responses to stress have been associated with increased risk for cardiovascular disease (e.g., Treiber et al., 2003), investigators began to examine the potential role of the exaggerated stress response in explaining how exposure to stress (and related psychological risk factors) led to heart disease. For example, several studies that have examined the relations between cardiovascular reactivity and hostility have found that hostile healthy young adults exhibited higher BP reactions than non-hostile young adults in response to interpersonal stressors or being harassed during mental tasks (e.g., Holt-Lunstad, Smith, \& Uchino, 2008; Neumann et al., 2011; Vella \& Friedman, 2009). In brief, although not all studies have shown these sorts of relations between behavioral risk factors for CAD and exaggerated cardiovascular reactions to stress (e.g., Chatkoff, Maier, Javaid, Hammoud, \& Munkrishna, 2009; Hernandez, Larkin, \& Whited, 2009), some support exists for this premise.

Because having a highly reactive cardiovascular system in response to stress is linked with increased risk for developing CAD (Brydon, et al., 2010; Krantz, Helmers, Bairey, \& Nebel, 1991; Strike, et al., 2004), it follows that exposure to positive emotional states or positive psychological phenomena would have the opposite effect. Essentially, positive emotions may 
“undo” the negative effects that normally result from stress (Fredrickson, Mancuso, Branigan, \& Tugade, 2000). For example, approaching a task optimistically might be hypothesized to result in smaller HR and BP reactions to that task than approaching it with less optimism.

Accumulating evidence suggests that forgiveness is associated with attenuated cardiovascular reactivity to stress, both immediately after a transgression and when thinking about the transgression at a later time (e.g., Larsen, et al., 2012). Over the past decade, several studies have examined whether forgiveness was indeed associated with smaller cardiovascular reactions to stress.

\section{The Physiology of Forgiveness}

There have been 19 studies that have examined whether forgiveness was associated with attenuated cardiovascular stress responses (see review by Larkin, Goulet, \& Cavanagh, 2015). Studies have examined both (a) differences between persons high and low in trait forgiveness on measures of cardiovascular arousal when exposed to stressful stimuli; and (b) differences between exposures to forgiving imagery versus a range of control scenes. Regarding the former type of study, multiple studies have found that those high in trait forgiveness exhibit attenuated cardiovascular responses when exposed to anger/betrayal recall tasks when compared with those low in trait forgiveness (Lawler, et al., 2003; Lawler-Row, Hyatt-Edwards, Wuensch, \& Karremans, 2011; Lawler, Younger, Piferi, Jobe, Edmundson, \& Jones. 2005). Witvliet and her colleagues have been at the forefront of examining the physiological effects of forgiveness by comparing exposure to forgiving imagery versus control scenes. Studies from her lab have reported that heart rate (HR), blood pressure (BP), and skin conductance were all significantly lower during imagined forgiveness scripts than during imagined unforgiving scripts (Witvliet, Ludwig, \& Vander Laan, 2001) or when imagining forgiving or not forgiving a personal offense 
from their own past (Witvliet, DeYoung, Hofelich, \& DeYoung, 2011). In sum, of the 19 studies that have examined associations between forgiveness and cardiovascular reactivity to stress, 17 of them have found some support for the stress-reducing effect of forgiveness. Although the pattern of findings varies across physiological parameters measured in these studies, results have consistently emerged for measures of HR and BP reactivity, the parameters of significant interest for researchers aiming to understand behavioral risk for cardiovascular disease.

\section{Apology and Forgiveness}

It has been well documented that the delivery of an apology by an offender is associated with a greater propensity for forgiveness (Bachman \& Guerrero, 2006; McCullough, Worthington, \& Rachal, 1997). People are more likely to forgive a transgressor following receipt of an apology versus receiving no apology, or when the victim perceives the transgression as unintentional instead of when the transgression is perceived as intentional (Struthers, Eaton, Santelli, Uchiyama, \& Shrivani, 2008). Also, following sincere apologies, victims are less likely to blame the transgressor, more likely to forgive, and report liking the transgressor more than if no apology or a poor apology was given (Darby \& Schlenker, 1982). Furthermore, apologies may decrease the likelihood of aggression by the victim (i.e., revenge) following a transgression (Ohbuchi, Agarie, \& Kameda, 1989). Clearly, apology produces many interactional benefits in addition to increasing the likelihood of forgiveness.

Apology is a powerful, simple manipulation that can be easily implemented in a laboratory setting. However, the effects of apologies have not been widely studied, and even less so among studies in which physiological responses to stress were measured. In fact, only three studies could be located in which the physiological effects of an apology following an in-session 
transgression were examined (Anderson, Linden, \& Habra, 2006; Kubo, Okanoya, \& Kawai, 2012; Whited, Wheat, \& Larkin, 2010).

Anderson et al. (2006) examined the effects of hostility and apology on cardiovascular recovery from a transgression among undergraduate students. Their sample consisted of 184 (92 male, 92 female) undergraduate students with a mean age of 19.9 years. The sample was $48 \%$ Asian, 42\% Caucasian, 4\% Indo-Canadian, and 6\% other ethnicities. Using a 3 x 3 design, they divided participants based on hostility level (high, medium, low) and apology condition (apology, pseudo-apology, no apology). Participants performed a mental arithmetic task, during which they were subjected to verbal harassment by the experimenter. Harassments were scripted and delivered via an intercom system. After completion of the mental arithmetic task, the experimenter entered the room and either gave a good apology, a pseudo-apology, or no apology. The good apology script was as follows: Listen, “(participant name), I’m really sorry for being so rude to you a few minutes ago. If I upset you while you were counting, that is totally my fault. I was speaking to you that way on purpose as part of the experiment. But I do feel bad about this. I'm usually much more courteous and professional. I'm sorry” (p. 357). The pseudoapology was designed to be insincere and was “You seemed a little agitated there. Well, I’m sorry if you got upset during the task, but it's important for you to go really fast, or the experiment isn’t going to work”(p. 357). A ten minute recovery period followed during which systolic (SBP) and diastolic blood pressure (DBP) and HR were recorded. The authors reported a significant interaction effect for SBP recovery; those in the high hostility group who did not receive an apology exhibited the slowest SBP recovery. Participants receiving the good apology had the fastest SBP recovery. There also was a main effect for hostility; higher hostility was associated with slower SBP recovery. 
Similar to Anderson et al. (2006), Kubo et al. (2012) found that delivering an apology produced attenuated cardiovascular responses. In their study, 48 undergraduate students (24 male, 24 female, mean age $=20.5$ years) wrote short essays about social problems, and received handwritten, insulting feedback from the experimenter about their composition. Half of the participants received a simple apology at the end of the insulting feedback, while half received no apology. The authors reported that those who did not receive an apology had a significant increase in HR after reading the feedback, while those who received an apology did not.

Whited et al. (2010) examined: (a) how those high and low in trait forgiveness differed in their physiological responses to an in-session transgression, and (b) how an apology following the transgression influenced the duration of their physiological responses. Their sample consisted of 79 undergraduate students (29 men, 50 women) ages 18-24 years. They employed a $2 \times 2 \times 2$ between subjects design. The factors were trait forgiveness level, (high, low), apology condition, (elaborate apology, no apology), and sex of participant. After a 15-minute rest period, participants performed serial subtraction for 5 minutes. At 30 seconds, 2 minutes, and 4 minutes, the experimenter verbally harassed participants telling them that they weren't performing well. Following the task, half the participants received the scripted apology used by Anderson et al. (2006) from the experimenter and half did not. SBP, DBP, mean arterial pressure (MAP), heart rate variability, and HR were measured throughout the session. Results revealed a main effect for trait forgiveness for both DBP and MAP recovery, with those high in trait forgiveness recovering more quickly than those low in trait forgiveness. The apology condition also had a significant effect on DBP and MAP recovery rates; however, sex moderated the effect. Among women, those who received an apology recovered more quickly than those who did not receive an apology; however, in men, those who received an apology recovered more slowly than those 
who did not receive an apology. These findings suggested that although apology facilitated cardiovascular recovery from harassment for women, apology was of no benefit for men, and actually prolonged the blood pressure response. Because this finding was not anticipated and it has implications for how men and women resolve challenging interpersonal situations in healthy ways, the proposed study was designed to replicate this finding and further examine how men and women respond to apologies in different ways.

\section{Sex Differences in Responses to Apology}

Because the study conducted by Whited et al. (2010) is the only study showing disparate physiological responses to apology between men and women, it is important to replicate this finding. Additionally, in order to comprehend the nature of the observed sex differences fully, it is important to review the literature on sex differences in response to apology that pertain to other important outcome variables typically measured using self-reported assessments. Among these studies are important clues pertaining to how men and women respond differently to apologies. For example, Thomas, White, and Sutton (2008) reported that women were more willing to forgive a transgressor who took responsibility for a transgression than men while men were more willing to forgive a transgressor who did not take responsibility for the transgression than women. Accordingly, women forgive transgressors when they take responsibility for their actions (i.e., they apologize for engaging in the behavior), but men were less apt to forgive transgressors who apologize. Interpreting the sex differences in cardiovascular recovery observed by Whited et al. (2010) in light of these findings, it is possible that the women in Whited's study forgave the experimenter and experienced a rapid recovery in blood pressure arousal, but men did not forgive the experimenter and elevated blood pressures were maintained. However, self-report ratings of forgiveness of the experimenter following the recovery period 
did not reveal any sex differences or moderation by participant sex, suggesting that the sex difference only emerged physiologically. Alternatively, both sexes could have arrived at comparable levels of forgiveness by the time the measure of forgiveness was obtained; women could have forgiven the offense more quickly than the men during the 10 minute recovery period.

Novelty Effect. Another possible explanation for the sex differences in blood pressure recovery observed in Whited et al. (2010) is that men are experience hearing apologies less than women. Indeed, research has found that women do apologize and receive apologies more frequently than men (Holmes, 1989; Schumann \& Ross, 2010). The types of apologies that men and women offer following transgressions are also different. Gonzalez, Pederson, Manning, and Wetter (1990) found that when women apologize, they produced longer accounts and more excuses, justifications, and concessions than men. Furthermore, women typically express responsibility more than men, and are more likely to express remorse for their conduct than men (Gonzalez et al., 1990). The scripted apology used in the Anderson et al. (2006) and Whited et al. (2010) studies fits the model of apologies typically given and received by women. Because men apologize and receive apologies less frequently than women, and the scripted apologies used in these studies were more similar to apologies given and received by women, it is possible that the given apology was quite novel to the men. Consequently, the lack of blood pressure recovery observed among men who received the apology may reflect a "novelty" effect. Conversely, women responded to the apology with a more rapid recovery because they were familiar with receiving apologies than men and the apology was similar to the types of apologies they typically receive. 
Evolutionary Model. Another possible explanation is that men and women deal with conflict in different ways. According to an evolutionary model, men tend to cope by confronting the conflict or by running away (fight or flight), whereas women are more prone to talk things out and seek understanding (tend and befriend) when dealing with conflict (Miller, Worthington, \& McDaniel, 2008). It is possible that the apology used in the Whited et al. study activated a social norm among women, leading to quicker recovery. In men, the apology may have challenged a social norm, to "fight” (e.g., remain irritated) in the face of conflict, thus further aggravating them.

Perceived Intentionality and Sincerity. Struthers, Eaton, Santelli, Uchiyama, and Shirvani, (2008) found that when interpersonal transgressions seemed intentional, individuals were less likely to forgive the transgressor. They also found that when the apology seemed insincere, the participant was less likely to forgive than if no apology was given. This may also explain why men’s blood pressures recovered more slowly after an apology than if no apology was given. It is possible that men perceived the transgression as intentional and/or the apology as insincere. However, because these variables were not measured by Whited et al. (2010), it is unclear to what extent they contribute to understanding the sex differences in blood pressure recovery following apology. Furthermore, the content of the apology actually revealed that the experimenter engaged in the harassment intentionally "as part of the study.” Men who received the apology may have been more irritated that they were intentionally harassed than women, and consequently, blood pressure elevations were sustained for longer durations.

Types of Apology. "In general, a bad apology is not better than no apology at all” (Roschk \& Kaiser, 2013, p. 300). Apologies typically consist of any combination of "giving detailed explanations, accepting responsibility, expressing remorse, showing consideration, 
begging for forgiveness, promising future good deeds” (Ohbuchi, Kameda, \& Agarie, 1989, p. 219). The type of apology one delivers is an important factor in determining if one will forgive a transgressor or not. More empathetic, more intense, and more timely (shortly after the transgression) apologies are more likely to facilitate forgiveness and restore relationships than less empathic, intense, or distal apologies (Roschk \& Kaiser, 2013). Darby and Schlenker (1982) found that more elaborate apologies resulted in less blaming of the transgressor and more forgiveness towards the transgressor than less elaborate apologies. However, because men tend to offer shorter, less elaborate apologies than women (Gonzalez et al., 1990), it may be that the type of apology used in the Anderson et al. (2006) and Whited et al. (2010) studies matched the type of apology that would facilitate forgiveness among women but not men. Women may be more likely to forgive when an elaborate apology is given, and men may be more likely to forgive when a short, simple apology is given.

\section{Aims of the Proposed Study}

The purpose of the proposed study is twofold. First, because Whited et al. is the only study to report differential responses of men and women in BP recovery following receipt of an apology, it was important to replicate the finding that men had a slower BP recovery (indicating less forgiveness) following an apology than if they did not receive an apology, and that apology had the opposite effect on BP recovery among women (Whited et al., 2010). The second aim of this study was to examine the effects of different types of apologies on cardiovascular recovery from a staged interpersonal harassment among men and women. This study employed an elaborate apology and a no apology group identical to the two groups used by Whited et al. (2010). Additionally, to test whether the sex difference was related to the type of apology given, a third group receiving a simple apology was used. It was expected that both participant sex and 
apology condition would affect blood pressure recovery. We also predicted that we would see an interaction effect for participant sex and apology condition such that that women will have a quicker BP recovery following the elaborate apology in contrast to women receiving no apology (as found in Whited et al., 2010). We also expected that men will have a slower BP recovery following the elaborate apology compared to no apology (also found by Whited et al., 2010). Based upon the literature on sex differences in apologizing and receiving apologies, we expected that men would have a more rapid blood pressure recovery following the simple apology in comparison to men receiving either an elaborate apology or no apology. We did not expect the pattern of showing a more rapid blood pressure recovery following the simple apology to be observed among women.

\section{Method}

\section{Participants}

Seventy-seven participants (36 men; 41 women) were recruited from undergraduate classes at West Virginia University. Participants were predominantly Caucasian, and ranged in age from 18-25 years old. Participants were excluded if they reported smoking or using any kind of tobacco, had any chronic major health concerns (i.e., heart disease, cancer, diabetes), or were taking medications that influenced heart rate or blood pressure. One male participant was excluded from analyses due to being hypertensive. For complete demographic information of participants, see Table 1. Participants were asked to abstain from caffeine, alcohol, and vigorous exercise for two hours prior to the experiment. Sample size for this study was estimated using G*Power 3.1.9, by entering the study design as "a priori, ANCOVA: main effects and interactions," with an effect size of $f=.43, \alpha=.05$, and power of .80 . This effect size was obtained from Whited et al. (2010), in which BPs of men who received an apology recovered 
more slowly than men who received no apology, $F(1,26)=5.13, p=.03, \eta^{2}=.16$, and women who received an apology recovered more quickly than women who did not receive an apology, $F(1,47)=8.71, p<.01, \eta^{2}=.16$. This calculation revealed that a sample size of 74 would be adequate for detecting an effect of this magnitude.

\section{Measures}

\section{Cardiovascular measures}

Heart rate (HR). HR was measured using a Polar heart rate monitor Model 810i (Lake Success, New York). This device sends ECG signals from a sensor strapped below the participants’ chest to a receiver attached to a computer for purposes of measuring HR continuously throughout data collection. Three measures of heart rate variability (HRV) were determined from the continuous HR signals: standard deviation of the normal sinus interbeat interval-to-normal sinus interbeat interval (SDNN); low frequency (LF) HRV, and high frequency (HF) HRV. HR signals were examined for clarity and subjected to analysis using Kubios HRV v2.0 software (Niskanen et al., 2004).

Blood pressure. An Industrial and Biomedical Sensors, Inc. Model SD-700A (Waltham, MA) automated sphygmomanometer was used to measure SBP, DBP, and MAP. This device includes an automated occluding cuff positioned on the brachial artery of the participants' nondominant arm. The cuff contains a microphone that detects Kortokoff sounds, ensuring accurate BP measurement. Maximum cuff inflation was set at 165 millimeters of Mercury (mm Hg) and rate of deflation set at $3 \mathrm{~mm} \mathrm{Hg}$.

\section{Self-report measures}

Demographic form. A short demographic form used in previous studies in the Behavioral Physiology laboratory (e.g., Prentice, 2009) was used in this study. This questionnaire included 
items pertaining to age, gender, height, weight, race/ethnicity, year in school, and parental socioeconomic status. The form also included general questions about participants' health status and behaviors (See Appendix A).

Multiple Affect Adjective Checklist-Revised (MAACL-R). The MAACL-R (Zuckerman \& Lubin, 1985) is a checklist-type questionnaire containing 66 adjectives describing state and/or trait affect. Participants were asked to complete the MAACL-R several times during the experiment, endorsing adjectives based on how they felt during the preceding phase of the experiment. This measure has five sub-scales: Anxiety, Depression, Hostility, Positive Affect, and Sensation Seeking, which have all shown good internal consistency reliability in previous studies (Cronbach’s alphas range from .68 to .91; Lubin, Van Whitlock, Reddy, \& Petren, 2001).

Forgiving Personality Inventory (FPI). The Forgiving Personality Inventory is a 33item scale that measures trait-forgiveness. It has demonstrated good internal consistency (alpha = .93) and good test-retest reliability in previous studies (correlation over 2-month period = .86; Kamat, Jones, \& Row, 2006). In the current study, the FPI demonstrated good internal consistency (alpha $=.91)$. Participants completed this questionnaire during screening prior to coming into the laboratory.

Rumination Reflection Questionnaire (RRQ). The RRQ assesses two factors, rumination and reflection. Rumination is a tendency to review perceived injustices, threats, or losses that one has experienced. For this study we were only interested in rumination and therefore we only used the first 12 items, which assess rumination. The rumination factor (12 items used in this study) has previously demonstrated good internal consistency (coefficient alpha = .90; Trapnell \& Campbell, 1999). In the current study, internal consistency was good 
$($ alpha $=.88)$. Participants completed this questionnaire during screening prior to coming into the laboratory.

Midlife Developmental Inventory (MIDI). The MIDI is a 30-item questionnaire that assesses 6 personality factors: Agency (alpha $=.79)$, Agreeableness (alpha $=.80)$, Openness to experience (alpha $=.77)$, Neuroticism (alpha $=.74)$, Extraversion (alpha $=.78)$, and Conscientiousness (alpha = .58; alphas obtained from Lachman \& Weaver, 1997), and is appropriate for participants age 18-88. Each item is single adjective; the participant endorses to what degree the adjective describes them on a 4-point Likert-type scale. In the current study, Agency $($ alpha $=.64)$, Agreeableness $($ alpha $=.95)$, Openness to experience $($ alpha $=.84)$, Neuroticism (alpha $=.58)$, Extraversion $($ alpha $=.91)$, and Conscientiousness $($ alpha $=.89)$ scales had reasonable internal consistency. Participants completed this questionnaire during screening prior to coming into the laboratory.

Post-Experiment Questionnaire. The first six items on the post-experimental questionnaire used in this study were identical to the post-experiment questionnaire used by Whited et al., (2010). In addition to these six items, five items that assess how the participant received the apology were included (See Appendix B).

\section{Experimental design}

This study employed a 2 x 3 factorial design. The factors were Sex of participant (men, women), and Condition (elaborate apology, simple apology, no apology). Participants were randomized to experimental condition using a number list generated from a random number table, with approximately equal numbers of men and women in each group. 


\section{Procedure}

Participants completed the demographic and other pertinent questionnaires online using the SONA system, and those who expressed an interest and were eligible were invited to schedule a laboratory session. Upon entering the laboratory, the participant met the experimenter, who was dressed in a white lab coat and behaved in a professional manner. There was one male experimenter and two female experimenters. The male experimenter was 25 years old and both female experimenters were 21 years old; all three experimenters were Caucasian. Sex of experimenter was counterbalanced across men and women participants so that approximately half of them interacted with a same sex experimenter (42 participants) and the other half with an experimenter of the other sex (35 participants). Upon obtaining informed consent (see Appendix C for approved consent agreement), the experimenter measured the height and weight of the participant, and confirmed that he or she had abstained from caffeine, alcohol, and exercise for the previous two hours. The experimenter then left the room so the participant could attach the Polar heart rate monitor around his or her chest privately. The experimenter then attached the blood pressure cuff to the participants' non-dominant upper arm and HR and BP were examined to assure signal clarity. Participants were then instructed to sit with both feet on the floor for a 15-minute rest period. Blood pressure measurements began eight minutes into the rest period and were taken every two minutes for the remainder of the rest period. Following the rest period, participants completed the MAACL-R based upon how they were currently feeling.

Participants were then given instructions regarding a five-minute serial subtraction task. During the task, participants were verbally harassed at 30 seconds, 2 minutes, and 4 minutes, identical to harassment used by Whited et al. (2010). For the first harassment, the experimenter 
stated “Look [participant name], you're subtracting way too slow. You've got to do it much faster. Begin again at 8,000.” The second prompt was “[participant name], you're still too slow and inaccurate. This can’t be your best. Now try it again from 6,190.” For the third and final harassment, the experimenter said "You're obviously not good enough at doing this, now try harder. Keep going from 5,066.”

After the task period, a second MAACL-R was administered with the instructions to complete it based on how the participant felt during the preceding task period. Blood pressure measurements continued during an 11 minute recovery period. Within the first two minutes of recovery, the experimenter returned to collect the questionnaire, at which time the experimenter collected the questionnaire and apologized if the participant was in one of the apology groups, or simply collected the questionnaire if the participant was in the no-apology group. There were two different apology scripts. The first one (elaborate), taken from Anderson (2006) and Whited et al. (2010) was:

“[Participant name], I’m really sorry for being so rude to you a few minutes ago. If I upset you while you were counting, that is totally my fault. I was speaking to you that way on purpose as part of the experiment. But I do feel bad about this. I'm usually much more courteous and professional. I'm sorry."

The second apology was a simple apology indicating that the experimenter intended to verbally harass the participant. The experimenter stated, “As part of the experiment I was rude to you. I am sorry," (For a description of the pilot testing for the simple apology, see Appendix D). At the end of the recovery period, a final MAACL-R was administered. Participants then filled out the post-experiment questionnaire and were told that their names would not be attached to their responses so that they could express their feelings towards the experimenter freely. 
Finally, participants were debriefed concerning the study and compensated \$10 for their participation.

\section{Results}

\section{Data Cleaning and Reduction}

Prior to data analysis, BP measurements not meeting criteria established by Marler, Jacob, Lehoszky, and Shapiro, (1988) were examined and considered for deletion. Any systolic BPs below 70 mm Hg or above 250 mm Hg or any diastolic BPs below 45 mm Hg or above 150 mm Hg were replaced with the most proximate valid BP value within that experimental period. Furthermore, when pulse pressure between a SBP and its paired DBP was not at least $30 \mathrm{~mm} \mathrm{Hg}$, BPs that were inconsistent with their proximate BPs were replaced with the mean of two proximate, valid BPs. A total of 73 BP measurements (out of 2808 total BP measurements or $2.6 \%$ of BP measures) were flagged as questionable and replaced according to these criteria. Heart rate data were analyzed for artefacts using the Polar 810i software set at a low filtering level. This software replaces likely erroneous values typically observed when participants move excessively or the signal from the Polar Monitor is momentarily lost. Heart rates were then determined for each minute during the rest, mental arithmetic, and recovery periods. Any BP or HR measure that was not within 3 standard deviations of the group mean for that parameter was replaced with a value 2 standard deviations from the group mean. A total of 7 HRs (all from the same participant) that were greater than 3 standard deviations above the mean were replaced with values 2 standard deviations above the mean for the group.

Rest Period. Cardiovascular data obtained during the rest period was reduced as follows. One way repeated measures ANOVAs were conducted to examine variation that might occur in each cardiovascular parameter across each minute of the rest period. Analysis of resting SBP, 
$F(2,75)=.354, p=.703$ resting DBP, $F(2,75)=1.61, p=.203$, and resting $\operatorname{MAP}, F(2,75)=$ $.80, p=.451$, revealed no significant main effects, so BP values during the rest period were averaged to arrive at a mean resting level for each parameter (i.e., resting SBP, resting DBP, resting MAP). In contrast, the repeated measures ANOVA on resting HR revealed a significant main effect, $F(2,75)=10.18, p<.000, \eta_{p}{ }^{2}=.12$. Follow-up mean comparisons showed that minute $11(74.6 \mathrm{bpm})$ and minute $13(75.3 \mathrm{bpm})$ of the rest period were significantly lower than the other minutes during the rest period. However, because these differences did not indicate any systematic change in HR across the baseline period, HR was averaged across all 5 minutes of the rest period.

Because assessment of HRV is unreliable across durations as brief as one minute, interbeat intervals from all valid HR values during the rest period were subjected to HRV analysis, producing one measure at rest for each HRV parameter (SDNN, HF, LF). By convention, all HF and LF measures throughout the experiment were transformed using logarithmic transformations in order to normalize distributions for purposes of analysis.

Task Period. Repeated measures ANOVAs were also used to examine minute-to-minute differences in cardiovascular parameters during the mental arithmetic task. No significant main effect was observed for $\mathrm{HR}, F(4,75)=1.58, p=.178$, during the mental arithmetic task. However, a significant main effect was seen for SBP, $F(2,75)=16.75, \mathrm{p}<.000, \eta_{p}^{2}=.181$, DBP, $F(2,75)=3.47, p=.034, \eta_{p}{ }^{2}=.044$, and MAP, $F(2,75)=11.49, p<.000, \eta_{p}^{2}=.131$. Post-hoc mean comparisons indicated that SBP increased from the first minute $(M=125.4 \mathrm{~mm}$ $\mathrm{Hg}, S E=1.81)$ to the third minute $(M=131.9 \mathrm{~mm} \mathrm{Hg}, S E=1.52)$ of the mental arithmetic task. SBP at Minute $5(M=133.4 \mathrm{~mm} \mathrm{Hg}, S E=1.61)$ was significantly higher than SBP at Minute 1 , but not significantly higher than SBP at Minute 3. DBP also increased from the first minute ( $M$ 
$=68.7 \mathrm{~mm} \mathrm{Hg}, S E=1.35)$ to the third minute $(M=72.6 \mathrm{~mm} \mathrm{Hg}, S E=1.52)$ of the mental arithmetic task. DBP at minute $5(M=71.9 \mathrm{~mm} \mathrm{Hg}, S E=1.69)$ was not significantly different from DBP at minute 1 or minute 3. MAP showed the same pattern as SBP and DBP; MAP increased from the first minute $(M=87.6 \mathrm{~mm} \mathrm{Hg}, S E=1.06)$ to the third minute $(M=92.4 \mathrm{~mm}$ $\mathrm{Hg}, S E=1.13)$ MAP at the fifth minute of the mental arithmetic task $(M=92.4 \mathrm{~mm} \mathrm{Hg}, S E=$ 1.29) was significantly higher than MAP at minute 1 , but not higher than MAP at minute 3. SBP, DBP, and MAP all showed similar patterns during the mental arithmetic task; they each increased from minute 1 to minute 3 , but did not increase from minute 3 to minute 5 (see figures 1-4). For purposes of analyzing cardiovascular reactivity to the mental arithmetic task, measures of $\mathrm{HR}$ and BP were averaged across minutes to obtain average cardiovascular reactions to the entire task.

Because the goal of this study was to examine recovery following a stressor, it was necessary to confirm that participants were reactive to the mental arithmetic task. A series of paired-sample t-tests compared averaged resting and task levels of each cardiovascular parameter. Analyses of SBP, $t(76)=17.38, p<.000$, DBP, $t(76)=7.0, p<.000$, MAP, $t(76)=$ 12.65, $p<.000$, HR, $t(75)=14.98, p<.000$, and HF-HRV, $t(75)=4.24, p<.000$, were all reactive to the task, while SDNN, $t(75)=.23, p=.818$, and LF-HRV, $t(75)=1.35, p=.181$, were not reactive to the task. Because SDNN and LF-HRV were not reactive to the mental arithmetic task, these parameters were excluded from subsequent analyses.

Recovery Period. Individual values for each cardiovascular parameter were used to calculate area under the curve (AUC) using the formula used by Whited et al. (2010), Neumann, Waldstein, Sellers, Thayer, and Sorkin (2004), and Friedberg, Suchday, and Shelov (2007).

The formula that was used for each measure of BP was: 
Excursion $=(0.5 * 120) *(($ cardiovascular measure at recovery min 1$)+(2 *$ cardiovascular measure at recovery min 3$)+(2 *$ cardiovascular measure at recovery min 5$)+(2 *$ cardiovascular measure at recovery min 7$)+(2 *$ cardiovascular measure at recovery min 9) $+($ cardiovascular measure at recovery min 11)) - (cardiovascular measure at baseline * 600).

The formula that was used for HR was:

Excursion $=(0.5 * 60) *(($ HR at recovery min 1$)+(2 *$ HR at recovery min 2$)+(2 *$ HR at recovery $\min 3)+(2 * \mathrm{HR}$ at recovery $\min 4)+(2 * \mathrm{HR}$ at recovery $\min 5)+(2 * \mathrm{HR}$ at recovery $\min 6)+(2 * \mathrm{HR}$ at recovery $\min 7)+(2 * \mathrm{HR}$ at recovery $\min 8)+(2 * \mathrm{HR}$ at recovery $\min 9)+(2 * \mathrm{HR}$ at recovery $\min 10)+(\mathrm{HR}$ at recovery minute 11$))-(\mathrm{HR}$ at baseline *600).

The formula that was used for HRV parameters was:

Excursion $=(0.5 * 300) *((\mathrm{HRV}$ parameter during mental arithmetic $)+(2 * \mathrm{HRV}$ parameter during first 5 minutes of recovery) + (HRV parameter during second 5 minutes of recovery)) - (HRV parameter at baseline *600).

By transforming values into this measure of area, rate of recovery can be captured in a single value for each cardiovascular measure. A larger number, or larger area under the curve, indicates a more prolonged recovery.

Consideration of Covariates. Because family history of hypertension has been shown to be associated with exaggerated cardiovascular reactivity to stress and delayed recovery from stress in prior work (e.g., Frazer, Larkin, \& Goodie, 2002), it was considered as a potential covariate. Standardized residuals were used so that resting levels of each parameter could be covaried out of each reactivity cardiovascular parameter separately. A MANCOVA on 
cardiovascular reactivity across all cardiovascular parameters (SBP, DBP, MAP, HR, HF-HRV) was conducted using family history of hypertension as the independent variable. No significant effect was observed for family history of hypertension, $F(5,70)=.721$, $\mathrm{p}=.61$.

Other potential covariates were assessed by calculating correlation coefficients between each potential covariate and resting measures for each cardiovascular parameter. Continuous variables assessed as potential covariates included BMI and perceived SES. BMI was significantly related to resting SBP, $(r=.268, \mathrm{p}=.019)$. BMI was therefore considered a covariate in all SBP analyses.

\section{Cardiovascular Measures at Rest}

Participant Sex X Apology Condition (2 X 3) ANOVAs were conducted for each cardiovascular parameter to determine if there were any differences at resting levels between groups (BMI was used as a covariate in the SBP analysis). See the first panel of Figures 1-4 for means and standard errors for resting SBP, DBP, MAP, and HR. Analysis revealed that there was a main effect for Sex at rest for SBP, $F(1,70)=7.56, p=.008, \eta_{p}{ }^{2}=.098$, with men displaying higher SBPs at rest $(M=114.9 \mathrm{~mm} \mathrm{Hg}, S E=1.39)$ than women $(M=109.1 \mathrm{~mm} \mathrm{Hg}$, $S E=1.3)$. For SBP, the main effect for Apology Condition, $F(2,70)=2.39, p=.099$, and the Sex X Apology Condition interaction, $F(2,70)=.35, p=.706$, were not significant. There were no significant main effects or interactions for resting DBP [Sex, $F(1,71)=3.77, p=.056$, Apology Condition, $F(2,71)=.18, p=.834$, and Sex X Apology Condition, $F(2,71)=.28, p=$ .759] or resting MAP [Sex, $F(1,71)=.20, p=.887$, Apology Condition, $F(2,71)=.75, p=$ .477 , and Sex X Apology Condition, $F(2,71)=.28, p=.758]$.

There was a significant main effect for Apology Condition on HR during rest, $F(2,70)=$ 3.4, $p=.039, \eta_{p}{ }^{2}=.088$. Participants randomized to the "no apology" condition had significantly 
lower resting HRs $(M=71.9 \mathrm{bpm}, S E=1.85)$ than those randomized to the "simple apology" condition $(M=78.7 \mathrm{bpm}, S E=1.87)$. There were no significant differences between those assigned to the "elaborate apology" condition $(M=76.4 \mathrm{bpm}, S E=1.81)$ and either the simple apology group or the no apology group. There were no significant main effects or interactions for resting measures of HF- HRV.

\section{Cardiovascular Reactivity to the Task}

To examine cardiovascular reactivity to the mental arithmetic task, Sex X Condition ANCOVAs were conducted for each cardiovascular parameter, covarying resting levels. See the middle panel of Figures 1-4 for means and standard errors for SBP, DBP, MAP, and HR during the mental arithmetic task.

Systolic Blood Pressure. The ANCOVA on SBP reactivity to the mental arithmetic task revealed a main effect for Participant Sex, $F(1,69)=5.98, p=.017, \eta_{p}{ }^{2}=.08$. Men exhibited greater SBP reactivity to the task (covariate adjusted $M=132.9 \mathrm{~mm} \mathrm{Hg}, S E=1.53$ ) than women (covariate adjusted $M=127.6 \mathrm{~mm} \mathrm{Hg}, S E=1.41$ ). Neither the main effect for Apology Condition, $F(1,69)=.834, p=.439$, nor the Sex X Condition interaction, $F(1,69)=2.0, p=$ .137, was significant.

Diastolic Blood Pressure. The ANCOVA on DBP reactivity to the mental arithmetic task revealed a main effect for Participant Sex, $F(1,70)=6.33, p=.014, \eta_{p}{ }^{2}=.083$. Men exhibited greater DBP reactivity to the task (covariate adjusted $M=74.0 \mathrm{~mm} \mathrm{Hg}, S E=1.53$ ) than women (covariate adjusted $M=68.7 \mathrm{~mm} \mathrm{Hg}, S E=1.43$ ). Neither the main effect for Apology Condition, $F(1,70)=1.86, p=.163$, nor the Sex $\mathrm{X}$ Condition interaction, $F(1,70)=.562, p=$ .573 , were significant. 
Mean Arterial Pressure. Analysis of MAP during the mental arithmetic task yielded similar results to those of SBP and DBP. The ANCOVA on MAP reactivity to the mental arithmetic task revealed a main effect for Participant Sex, $F(1,70)=11.52, p=.001, \eta_{p}{ }^{2}=.141$. Men exhibited greater MAP reactivity to the task (covariate adjusted $M=93.7 \mathrm{~mm} \mathrm{Hg}, S E=$ 1.15) than women $(M=88.3 \mathrm{~mm} \mathrm{Hg}, S E=1.08)$. Neither the main effect for Apology Condition, $F(1,70)=1.38, p=.26$, nor the Sex X Condition interaction, $F(1,70)=.20, p=.816$, was significant.

Heart Rate. The ANCOVA on HR reactivity to the mental arithmetic task revealed no significant main or interaction effects. Neither the main effects for Participant Sex, $F(1,69)=$ 2.61, $p=.111$, or Apology Condition, $F(1,69)=.524, p=.595$, nor the Sex X Condition interaction, $F(1,69)=.474, p=.624$, were significant.

High Frequency Heart Rate Variability. Analysis of HF-HRV during mental arithmetic revealed a significant main effect for Sex, $F(1,69)=5.84, p=.018, \eta_{p}^{2}=.078$. Men had greater HF-HRV during the task (covariate adjusted $M=861.4 \mathrm{~ms}^{2}, S E=106.92$; while analysis was performed on logarithmic transformed scores, these means are not log-transformed) than women (covariate adjusted $M=539.4 \mathrm{~ms}^{2}, S E=101.41$ ). Because higher values of HF-HRV reflect greater parasympathetic activity, women exhibited a greater reduction in parasympathetic activity during the task than men. Neither the main effect for Apology Condition, $F(1,70)=$ $1.66, p=.198$, nor the Sex X Condition interaction, $F(1,70)=2.27, p=.111$, was significant.

\section{Cardiovascular Recovery}

AUC values were analyzed using 2 x 3 (Sex x Apology Condition) ANCOVAs for each cardiovascular measure. Resting cardiovascular measures were used as covariates in these 
analyses, and BMI was also used as an additional covariate in SBP analyses. See the final panel of Figures 1-4 for means and standard errors for measures of SBP, DBP, MAP, and HR during the recovery period.

Systolic Blood Pressure. Analysis indicated that there was no significant main effects for either Apology Condition, $F(2,69)=.354, p=.703$, or Participant Sex, $F(1,69)=.013, p=.911$ on SBP AUC. Likewise, the interaction between Sex and Apology Condition was not significant, $F(2,69)=1.38, p=.26$.

Diastolic Blood Pressure. For DBP AUC, the main effects of Participant Sex $F(1,70)=$ 2.21, $p=.142$, and Apology Condition, $F(2,70)=.069, p=.933$, were not significant. The Sex by Apology Condition interaction was also not significant, $F(2,70)=.50, p=.609$.

Mean Arterial Pressure. Like AUCs for both SBP and DBP, the main effects for Participant Sex $F(1,70)=1.24, p=.27$, and Apology Condition, $F(2,70)=.537, p=.587$, as well as the Sex X Apology Condition interaction $F(2,70)=1.01, p=.37$, on MAP AUC were not significant.

Heart Rate. Similarly, in regards to HR, the main effects of Participant Sex, $F(1,69)=$ $.816, p=.369$, and Apology Condition, $F(2,69)=.341, p=.712$, and the interaction of Participant Sex X Apology Condition, $F(2,69)=.851, p=.431$, were not significant.

$\boldsymbol{H F}-\boldsymbol{H R} \boldsymbol{V}$. For HF recovery, the Sex $F(1,69)=1.86, p=.177$, and Apology Condition, $F(2,69)=1.02, p=.365$, main effects were not significant. However, the Sex X Apology Condition interaction effect, $F(2,69)=4.28, p=.018, \eta_{p}{ }^{2}=.110$, was significant. Follow-up $F$ tests for simple main effects were conducted first on men and women separately, and then on each apology group separately to analyze the nature of the interaction. There were no differences in HF-HRV AUC between apology conditions for men, $F(2,32)=.659$, p = .524. 
However, for women, the main effect for Apology Condition was significant, $F(2,36)=4.85, p$ $=.014, \eta_{p}^{2}=.212$. Women who received an elaborate apology $\left(M=-2.0 \log \left(\mathrm{ms}^{2}\right), S E=94.9\right)$ had a faster HF-HRV recovery than women receiving a simple apology $\left(M=-377.5 \log \left(\mathrm{ms}^{2}\right), S E\right.$ =95.0). When divided by condition, the Sex main effect was significant for participants receiving the simple apology, $F(1,21)=10.73, p=.004, \eta_{p}{ }^{2}=.338$. Men receiving a simple apology $\left(M=44.6 \log \left(\mathrm{ms}^{2}\right), S E=95.0\right)$, had faster HF-HRV recovery than women receiving a simple apology $\left(M=-377.5 \log \left(\mathrm{ms}^{2}\right), S E=95.0\right.$; See Figures 5, 6). Means and standard deviations for cardiovascular parameters are presented in Table 2.

\section{Measures of Affect}

Scores on three MAACL-R subscales (Anxiety, Depression, and Hostility) were combined to obtain a single negative affect score for each measurement period. For means and standard deviations of positive and negative affective responses during the experiment, see Table

3. Because measures of positive and negative affect were positively skewed during rest, mental arithmetic, and recovery, all affect scores were transformed with using a square root transformation to reach normality. To test for differences in affect during the various stages of the study, repeated measures ANOVAs were completed for both positive affect and negative affect across rest, task, and recovery periods. Results showed significant change in affect for both positive, $F(2,152)=63.9, p<.000, \eta_{p}{ }^{2}=.457$, and negative affect, $F(2,152)=164.7, p<$ $.000, \eta_{p}^{2}=.684$. Mean comparisons revealed that negative affect increased during the mental arithmetic task $(M=9.3, S E=.59)$ and was significantly higher (more negative affect) than during rest $(M=1.9, S E=.25)$ or following recovery $(M=2.7, S E=.35)$. Conversely, positive affect was significantly higher during rest $(M=5.6, S E=.56)$ than it was immediately following the mental arithmetic task $(M=1.18, S E=.25)$ or the recovery $(M=3.8, S E=.41)$ periods. 
Rest Period. Sex X Apology Condition ANOVAs were conducted for both positive and negative affect at each stage of the study. There were no significant main effects for Sex, $F(1$, $71)=.436, p=.511$, or Apology Condition, $F(2,71)=.93, p=.399$, on negative affect at rest. However, there was a significant Sex X Apology Condition interaction effect, $F(2,71)=5.36, p$ $=.007, \eta_{p}{ }^{2}=.131$. Simple $F$-tests indicated that after the initial rest period, men randomized to the simple apology group had higher negative affect $(M=3.8, S E=.73)$ than men in the elaborate apology group $(M=1.14, S E=.67)$. There were no differences in negative affect between apology groups for women. Furthermore, men in the simple apology group had higher negative affect than women in the simple apology group $(M=1.2, S E=.44)$.

For positive affect, the main effects for Sex, $F(1,71)=.68, p=.413$, and Apology Condition, $F(2,71)=2.71, p=.073$, were not significant at rest. However, like negative affect, the Sex X Condition interaction was significant, $F(2,71)=9.7, p<.000, \eta_{p}^{2}=.215$. Men randomized to the no apology group had higher positive affect $(M=8.5$, $S E=1.37)$ than women assigned to the no apology group $(M=4.6, S E=1.08)$. Women assigned to the simple apology group had higher positive affect $(M=9.5, S E=1.48)$ than men in the simple apology group $(M=$ 3.3, $S E=1.54)$. Men in the elaborate apology group $(M=5.7, S E=.82)$ had higher positive affect than women in the elaborate apology group $(M=2.2, S E=.89)$. Thus, in the no apology and elaborate apology groups, men had higher positive affect than women during the initial rest period, but in the simple apology group, women had higher positive affect than men. Men in the no apology group had higher positive affect than men in the simple apology group. Women in the simple apology group had higher positive affect than women in the elaborate apology group. As these sex differences were not anticipated and there was no obvious explanation for them (as participants were all treated identically up to this point in time in the experiment), resting 
MAACL-R values were covaried in subsequent analyses of measures of affect during task and recovery periods.

Task Period. Negative and positive affect following the mental arithmetic task were analyzed by conducting comparable Sex X Apology Condition ANCOVAs, using resting affect scores as covariates. There was a significant Apology Condition main effect for negative affect, $F(2,70)=3.57, p=.034, \eta_{p}{ }^{2}=.092$. Those randomized to the simple apology condition reported higher negative affect (covariance adjusted $M=11.1, S E=.90)$ than those in the no apology $(M$ $=8.04, S E=.89$ ) and elaborate apology conditions (covariance adjusted $M=8.5, S E=.87$ ). The main effect for Sex, $F(1,70)=1.20, p=.276$, and the Sex X Apology Condition interaction, $F(2$, $70)=1.09, p=.342$, were not significant for negative affect during completion of the mental arithmetic task.

For positive affect, there was a significant Sex main effect after the mental arithmetic task, $F(1,70)=8.61, p=.005, \eta_{p}{ }^{2}=.110$. After the mental arithmetic task, men had higher positive affect (covariate adjusted $M=1.9, S E=.34$ ) than women (covariate adjusted $M=.69$, $S E=.32)$. The main effect for Apology Condition, $F(2,70)=1.62, p=.205$, and the Sex $\mathrm{X}$ Apology condition interaction, $F(2,70)=2.08, p=.133$, were not significant for positive affect during completion of the mental arithmetic task.

Recovery Period. Neither main effects for Sex, $F(1,70)=2.37, p=.128$, and Apology Condition, $F(2,70)=.446, p=.642$, nor the Sex X Apology Condition interaction, $F(2,70)=$ $.175, p=.84$, were significant for negative affect during the recovery period. Likewise, there were no significant main effects for Sex, $F(1,70)=1.37, p=.246$, and Apology Condition, $F(2$, $70)=.218, p=.805$, for measures of positive affect during the recovery period. The Sex X 
Apology Condition interaction, $F(2,70)=.478, p=.622$, was also not significant for positive affect during the recovery period.

\section{Post-experimental questionnaire}

Responses to the Post-Experimental Questionnaire indicated that both men $(M=3.7, S E$ $=.15)$ and women $(M=3.9, S E=.16)$ found the stress task employed in this study to be more stressful than typical stressful experiences they encounter in daily life. To examine responses to items on the Post-Experiment Questionnaire, a series of 2 X 3 (Sex by Apology Condition) ANOVAs were conducted (for any item asking about the apology, 2 X 2 ANOVAs were conducted). Means and standard errors for each item of the Post-Experiment Questionnaire are shown in Table 4. For purposes of presenting these results, only items with significant effects will be reported here.

Frequency of similar stressful tasks rating. There was a significant Sex main effect for the item "I often encounter tasks like the math task I encountered today," $F(1,71)=10.77, p=$ $.002, \eta_{p}{ }^{2}=.132$. Men endorsed encountering similar tasks $(M=2.7, S E=.17)$ more frequently than women $(M=1.9, S E=.16)$.

Experimenter feedback was helpful rating. There was also a significant Sex main effect for the item "The experimenter was instructed to give you feedback to help you perform on the math challenge. The experimenter was very effective at helping you to achieve your best performance,” $F(1,71)=9.69, p=.003, \eta_{p}{ }^{2}=.120$. Men rated the experimenter as more helpful $(M=3.3, S E=.22)$ than women $(M=2.3, S E=.21)$.

Experimenter supportiveness after the task rating. The Apology Condition main effect was significant for the item "The experimenter was supportive after the math task was completed,” $F(2,71)=11.86, p<.000, \eta_{p}{ }^{2}=.25$. Those in the no apology group rated the 
experimenter as less supportive $(M=3.2, S E=.17)$ than either those in the simple apology $(M=$ $4.3, S E=.17)$ or elaborate apology groups $(M=4.1, S E=.17)$.

Forgiveness Rating. There was also a significant Apology Condition main effect for the item “I forgave the experimenter," $F(2,71)=8.1, p=.001, \eta_{p}{ }^{2}=.186$. Participants in the no apology group $(M=4.0, S E=.13)$ reported forgiving the experimenter less than either participants in the simple apology $(M=4.7, S E=.13)$ or the elaborate apology groups $(M=4.4$, $S E=.13)$

Intentional Rudeness Rating. There was a significant Apology Condition main effect for the item “The experimenter intended to be rude," $F(2,71)=4.11, p=.02, \eta_{p}{ }^{2}=.104$. Participants in the no apology group $(M=3.5, S E=.23)$ rated the experimenter as less intentionally rude than participants in the simple apology $(M=4.4, S E=.21)$ group. There was no significant difference between the elaborate apology group $(M=4.1, S E=.21)$ and either the no apology or simple apology group on this item.

Sincerity of Apology Rating. There was a significant Apology Condition main effect for the item "The apology that you received was very sincere," $F(1,47)=4.42, p=.041, \eta_{p}{ }^{2}=.086$. Participants in the elaborate apology group $(M=4.5, S E=.14)$ rated the apology as more sincere than those in the simple apology group $(M=4.1, S E=.15)$.

\section{Forgiving Personality and Rumination}

Because Whited et al. (2010) found that trait forgiveness influenced cardiovascular recovery for certain parameters, supplementary analyses were conducted to determine whether trait-forgiveness influenced participants’ recovery following the task in the current study. Participants were divided into high $($ FPI Mean $=133.3, S D=9.7)$ and low $(F P I$ Mean $=111.2$, $S D=10.5$ ) forgiving-personality groups based on a median-split of scores on the Forgiving 
Personality Inventory (FPI). A series of 2 X 3 (Trait Forgiveness Group by Apology Condition) ANCOVAs was conducted to determine if high and low trait-forgivers differed in recovery for each cardiovascular parameter. Resting cardiovascular parameters served as covariates. No main effects or interaction effects were observed for any cardiovascular parameter measured during the recovery period.

A similar strategy was employed to examine the effects of trait-rumination on cardiovascular recovery. Again, a median-split was conducted on participants’ RuminationReflection Questionnaire (RRQ) scores to create two groups: high ruminators and low ruminators. A series of one-way ANCOVAs was conducted with the RRQ group as the independent variable and the area under the curve (AUC) for each cardiovascular parameter serving as dependent variables. Resting cardiovascular parameters served as covariates. Similar to trait-forgiveness, there were no significant main effects or interactions for any cardiovascular parameter during the recovery.

\section{Discussion}

The purpose of this study was to examine the effect of apology on cardiovascular recovery following an interpersonal transgression. Specifically, we aimed to replicate previous findings by Whited et al. (2010) who showed that men have a slower BP recovery following an apology and a faster BP recovery when they did not receive an apology, and that apology has the opposite effect on the BP recovery of women. Additionally, we sought to examine the effects of two different types of apologies (simple vs. elaborate) on cardiovascular recovery from harassment among men and women. This study employed a live transgression, and therefore cardiovascular responses during the transgression, and immediately following the transgression were assessed. 


\section{Cardiovascular Recovery following Apology}

Whited et al. (2010) found that men who received an apology following an experimental transgression had a slower DBP and MAP recovery than men who did not receive an apology, and women who received the same apology exhibited a more rapid DBP and MAP recovery than women who did not receive an apology. Contrary to the previous study, these findings were not replicated in the current study. Given that both studies employed an almost identical experimental method, the failure to replicate these findings suggests that the phenomenon may not be very robust or due to subtle contextual differences in the way these two studies were conducted. One difference noted between these two studies relates to the magnitude of cardiovascular arousal experienced by study participants. In Whited et al., the average DBP during the final minute of the mental arithmetic task was $75.2 \mathrm{~mm} \mathrm{Hg}$, reflecting an average response of $+12.3 \mathrm{~mm} \mathrm{Hg}$ from the resting DBP of $62.9 \mathrm{~mm} \mathrm{Hg}$. In the current study, the average DBP during the final minute of the mental arithmetic task was $71.9 \mathrm{~mm} \mathrm{Hg}$, which reflects an average response of $+8.8 \mathrm{~mm} \mathrm{Hg}$ from the resting DBP of $63.1 \mathrm{~mm} \mathrm{Hg}$. Average HR at the end of the mental arithmetic task was $96 \mathrm{bpm}$ in the Whited study (resting HR = $75.3 \mathrm{bpm}$; reactivity $=+20.7 \mathrm{bpm})$, whereas in the current study, the average HR at the end of the mental arithmetic task was 90.5 bpm (resting $\mathrm{HR}=76.4$ bpm; reactivity $=+14.1 \mathrm{bpm}$ ). Thus, the overall magnitude of the response in the current study was 28\% lower for DBP and 32\% lower for HR than in the study by Whited and colleagues (see Appendix E). In this regard, participants in the study by Whited et al. experienced greater cardiovascular arousal during the task and consequently, had larger values from which to recover. It is possible that differential sex effects in response to apology are only observed among transgressions that elicit substantial cardiovascular reactions. The bases for the reduced reactivity to the transgression observed in 
the current study are unclear, but could have been caused by several factors, including differences in the stimulus characteristics of the experimenters (e.g., appearance, interpersonal style) or the harshness with which the feedback was given during the task. For example, in the Whited et al. study, the female experimenter appeared strictly professional; she wore a buttoned lab coat, glasses, and her hair pulled back in a tight bun. In the current study, the female experimenter's appearance was more casual; she wore an unbuttoned lab coat, casual clothing underneath the lab coat, loose-hanging hair, and one female experimenter had a nose ring. It is possible that experimenters in Whited and colleagues study were viewed as authority figures, while experimenters in the current study were viewed as students. Thus, participants were less reactive when being harassed by perceived peers than when being harassed by perceived authority figures.

However, the reduced HR and BP reactivity observed between these two studies was not observed in self-reported ratings of stressfulness of the task or affective responses. Participants in both studies rated the task as equally stressful and showed similar patterns of negative and positive affective responses. One explanation of why participants between the studies did not differ in regard to the self-reported stressfulness of the task is that in both studies the PostExperimental Questionnaire was completed after the recovery period, 12-13 minutes after the end of the stress task. Similarly, the MAACL-R was completed after both the stress task and the recovery period. It is possible that since the measures were completed after the stress task and recovery period, the actual physiological arousal experienced during these periods may have had less influence on participants’ responses.

A second aim of the study was to extend the work of Whited et al. (2010) by adding a simple apology group for purposes of comparison. Based upon previous literature about the 
types of apologies males typically receive during daily life, it was hypothesized that men who received a simple apology would exhibit a faster blood pressure recovery than men who received either the elaborate apology or no apology. Contrary to hypotheses, there were no significant differences in blood pressure recovery rates among men who received elaborate, simple, or no apologies. Furthermore, there were no differences in blood pressure recovery rates among women who received elaborate, simple or no apologies. The simple and elaborate apologies were designed to be similar in content and meaning, but differed in length. At least with respect to HR and BP, both sexes recovered similarly regardless of whether they received an apology or not and whether they received an elaborate or simple type of apology. Indeed, responses to the post-experimental questionnaire indicated that both men and women in each apology condition rated the apologies as equally sincere and similar to apologies that they normally received.

Whited et al. (2010) also found that participants’ levels of trait-forgiveness influenced their cardiovascular recovery from harassment, such that both men and women with high traitforgiveness exhibited faster MAP and DBP recovery regardless of whether they received an apology. This finding also was not replicated in the current study. This is not all that surprising, however, given the differences in how measures of trait-forgiveness were obtained and used in both studies. In contrast to the current study, Whited et al. (2010) specifically selected participants based on levels of trait-forgiveness; thus all participants were drawn from either the bottom or top tertile (approximately) on the trait-forgiveness spectrum of the screening sample. In the current study, participants' trait-forgiveness was measured, but not utilized in selecting participants to invite to the laboratory portion of the study. To differentiate between "high" and "low" trait-forgivers, a median-split of scores on the forgiving personality inventory was conducted. Naturally, the difference between "high forgivers" and "low forgivers" on the FPI in 
the current study was not as great as it was in the study by Whited et al. In this regard, the current study was not designed to replicate this finding and therefore, less likely to detect any differences between "high" and "low" forgivers. It should also be noted that the difference in selecting participants between these two studies may also be responsible for the failure to replicate the sex differences in response to apology in the current study. Because the differential sex response to apology was not moderated by trait-forgiveness in the study by Whited et al., however, it is unclear how the different selection strategies resulted in the inconsistent results. Although the current study did not replicate findings that participant sex and apology type influenced BP recovery, a significant interaction effect between apology condition and sex was detected for one measure of HRV during recovery. Consistent with hypotheses, women in the elaborate apology condition experienced a faster HF-HRV recovery than women in the simple apology group. Furthermore, when a simple apology was given, men experienced a faster HF-HRV recovery than women. Because HF-HRV is an indicator of parasympathetic activity, this means that women who received the elaborate apology returned to resting levels of parasympathetic activity faster than women who received the simple apology. Likewise, when a simple apology was given, men returned to resting levels of parasympathetic activity faster than women. This finding indicates that men recovered more rapidly following the simple apology compared to women's recoveries. This is consistent with the study hypotheses that men may respond more favorably to simpler apologies than women, although this effect appears to be limited to recovery of the parasympathetic response to stress. Whited et al. did not examine HRV recovery, so direct comparisons between Whited et al. and the current study in regard to HRV parameters cannot be made. 
Previous research suggests that women tend to give/receive longer, more elaborate apologies than men (Gonzalez et al., 1990). Consistent with this literature, women who received an elaborate apology in this study physiologically recovered from the experimental transgression faster than women who received a simple apology. It is possible that this physiological resolution occurred because it facilitated the process of forgiveness and it was similar to apologies that women typically receive in daily life. However, support for this interpretation was not evident in findings from the post-experiment question on familiarity of the type of apology given during the study. Women rated the simple and elaborate apologies equally in terms of how similar they were to apologies they typically received as well as overall ratings of forgiveness of the experimenter. It should be noted, however, that these ratings were made at the end of the ten minute recovery period and the differential rate of recovery could have occurred during earlier minutes of the recovery period.

Because HF-HRV is thought to measure parasympathetic activity, and this was the only cardiovascular parameter that had significant apology effects, it is important to consider why differential sex effects were observed for this underlying measure of autonomic functioning, but not with measures of BP and HR. In contrast to HF-HRV, HR is jointly influenced by parasympathetic and sympathetic innervation. If heart rate reactivity during transgression was solely driven by reduced parasympathetic activity, a comparable Sex X Apology Condition interaction would have been observed for HR. However, this was clearly not the case. In fact, the correlation between change in HF-HRV and change in HR to the task was only moderately, albeit significantly, correlated $(r=-.58, p<.001)$, indicating that the increased HR was being jointly influenced by sympathetic activation and parasympathetic withdrawal. BP, like HR, is influenced by both branches of the sympathetic nervous system (alpha and beta) and 
parasympathetic innervation of the heart, in addition to other peripheral influences (e.g., nitric oxide release in vascular walls, kidney regulation of fluids). Thus, if the impact of the presence and type of apology is confined to the parasympathetic nervous system, as seems evident in the current study, it was less likely to influence BP than HR due to the many other regulatory factors that affect BP. Indeed, the correlation between change in HF-HRV to the task and change in all parameters of BP were lower.

One possible explanation for the different types of arousal seen in the two studies is that the relationship with the person who transgresses and subsequently offers an apology determines whether the parasympathetic or the sympathetic system modulates arousal. For example, in Whited et al., (2010) the transgressors were likely seen as authority figures due to their strictly professional dress and interpersonal demeanor. The arousal in that study was predominantly modulated by the sympathetic nervous system. However, in the current study, when transgressors were more likely viewed as peers, arousal was modulated by the parasympathetic system. Thus, it is possible that when one is harassed and receives an apology from a peer, arousal is modulated by a reduction of parasympathetic activity rather than increased sympathetic nervous system activity. However, when one is harassed and receives an apology from someone that they don't know or like, arousal is modulated by an increase in sympathetic activity.

\section{Affective Response and Recovery from Stress}

Across all participants, self-reported affect showed predictable effects. Negative affect increased from rest during the mental arithmetic task and declined during the recovery period. Conversely, positive affect was elevated at rest and declined during mental arithmetic. Following the recovery period, positive affect was higher than it was during the task, but not as 
high as it was during the initial rest period. Again, self-reported affective responses highlighted the effectiveness of the stress task employed in this study.

In the current study, men endorsed higher levels of positive affect than women immediately following the mental arithmetic harassment task. One explanation for the differences in blood pressure reactivity to stress between sexes is that men and women differed on their affective responses to the mental arithmetic transgression. In the current study, men elicited higher BP responses to the transgression than women. In this regard, men responded to the task with greater physiological responses than women and women responded with greater affective responses than men. Indeed, this finding is congruent with previous studies that examined suppression of emotion and physiological arousal. Several studies (Goldstein, Edelberg, Meier, \& Davis, 1988; Gross, 1998; Gross \& Levenson, 1993; Vogele \& Steptoe, 1993) have showed that when one suppresses emotion, especially anger, they experience greater physiological reactivity to a stressful task. In the present study, men’s smaller affective response could be viewed as emotional suppression, resulting in a larger physiologic response.

There were no main effects for apology condition or participant sex on either positive or negative affect during the recovery period. This indicates that while men reacted differently to the experimental task than women with respect to both BP and affective responses, no differential sex effects were observed during the recovery period. However, it needs to be recognized that women exhibited larger reductions in positive affect in response to the experimental transgression, and consequently, may have perceived the apology as being more desirable and necessary than men. Because the transgression was experienced less negatively by men, they may have perceived the need for apology differently than women. 


\section{Post-Experimental Questionnaire}

Although no condition or sex differences were detected for recovery of affective responses or for $\mathrm{HR}$ or $\mathrm{BP}$ responses to the experimental transgression, those who did not receive an apology reported less forgiveness of the experimenter than either those in the simple or elaborate apology groups. There was no difference in self-reported forgiveness of the experimenter between the elaborate and simple apology groups. This finding is consistent with previous literature that suggests that providing an apology increases the probability of forgiveness.

Both those who received the simple apology and elaborate apologies rated the experimenter as less intentionally rude than those who didn't receive an apology. This indicates that those who received a simple or elaborate apology listened to and believed the apology (in which the experimenter stated that they were rude on purpose). Those who did not receive an apology perceived the transgression as less intentional than those who received an apology. This was expected, as both apologies stated that the transgression was intentional. Interestingly, those who did not receive an apology viewed the transgression as less intentional, but did not report as much forgiveness as those who received an apology. This finding is contrary to results of Struthers et al. (2008), who reported that when transgressions seemed intentional, individuals were less likely to forgive. However, the current study employed an experimental transgression that was likely of a lesser magnitude of severity when compared with the sorts of interpersonal transgressions that occur in real life among people with whom participants have ongoing relationships. In the current study, participants in the no apology condition were never informed that the actions of the experimenter were intentional and may not have perceived them as much of a transgression as those who received apologies. Another possible explanation for this 
discrepant finding is that in the current study, those who received an apology may have been operating under a demand characteristic to report more forgiveness due to feeling social pressure to forgive following the delivery of the apology.

Responses to the post-experimental questionnaire did not support the hypothesis that men and women would react differently to the elaborate and simple apologies due to a 'novelty effect.' Indeed, men and women rated the two apologies as equally sincere and equally similar to apologies that they normally receive.

\section{Limitations of the study}

There were some limitations to this study. First, the apology in the simple and elaborate apology conditions was delivered two minutes into the recovery period. Certainly, significant recovery took place during the two minutes between the end of the mental arithmetic task and the delivery of the apology. Because this recovery took place before the delivery of the apology, it was not influenced by the apology. It is likely that during this two -minute period the most rapid recovery took place. In future research examining cardiovascular recovery following an apology, it will be important to give the apology as soon as possible after the transgression takes place to evaluate its full effect. By doing so, the apology will influence the entire recovery period and its influence can be fully assessed. Furthermore, the experimenters were aware of which condition the participants were in, which may have influenced how the experimenter behaved during the experiment, and thus influenced the data.

Another limitation to this study was the time of the semester that men and women were recruited. Significantly more women signed up towards the beginning of the study, which was mid-way through the Fall 2014 semester. Women continued to participate through the end of this semester and throughout the entire Spring 2015 semester. Men did not sign up for the study 
nearly as readily as women, and thus, recruitment took longer. In fact, at the beginning of the Fall 2015 semester, the researcher made announcements to undergraduate psychology courses that the study needed men to participate in order to complete data collection for men. Data collection for over half of the men in this study was conducted during the Fall 2015 Semester using this strategy. It is possible that differences exist between volunteers who participate at the beginning of semesters and those who participate at the end of semesters. Because the majority of men participated at a different time of the semester than women, any sex differences that emerged may be influenced by this difference in participant recruitment and selection strategies employed in the current study.

It is also important to note that while receiving an apology increases the likelihood that the victim will forgive the transgressor, apology is only one behavior that influences probability of forgiveness. Other aspects that may influence whether or not one forgives a transgressor include one's moral beliefs, whether restitution occurs, the age of the victim, and quality of the relationship between the victim and transgressor (McCullough \& Witvliet, 2002). Many people (both religious and non-religious) believe that forgiving a transgressor is the right thing to do (Kinnier, Kernes, \& Dautheribes, 2000). Clearly, one’s moral beliefs regarding forgiveness will influence the likelihood that one will forgive, even in artificially constructed transgressions occurring in laboratory settings. Offering restitution attempts to remove the physical loss that occurred during the transgression. Indeed, when a transgressor makes restitution, or offers reparations for the transgression committed, the likelihood that the victim will forgive increases (Carlisle et al., 2012). Additional research suggests that the age of the victim is related to forgiveness; older victims are more likely to forgive than are younger victims (Darby \& Schlenker, 1982). Furthermore, the type of interpersonal relationship between the victim and 
transgressor affects forgiveness. When the victim feels close to or secure in their relationship with the transgressor, forgiveness is more likely to occur (McCullough \& Witvliet, 2002). It is conceivable that the process of forgiveness between intimate friends or partners looks much different that the process of forgiving a transgressor with whom one is not close. Furthermore, severity of a transgression will also affect forgiveness. In the current study, the behavior of the experimenter during the mental arithmetic task is likely different from interpersonal transgressions that individuals experience outside of the laboratory. It is possible that many participants did not view the experimenter's behavior as an interpersonal transgression. Clearly, several aspects of apology that influence forgiveness were not assessed by this study.

Another limitation to this study is that numerous analyses were conducted. It is possible that the few significant findings reported were due to an increased Type I error rate, given the large number of analyses that were conducted.

Finally, the sample in the current study was relatively homogenous. Participants were predominantly Caucasian, ranging in age from 18-25 years old. All participants were undergraduate university students. Also, because this study examined forgiveness following an apology, it is important to consider the possibility that participants who volunteered for the study differed from those who did not participate in relation to their likelihood of forgiving. This study would need to be conducted with a more heterogeneous community sample to determine if the observed effects are consistent across populations.

\section{Conclusions}

This study sought to replicate the finding by Whited et al. (2010) that men and women recovered differently from interpersonal transgressions depending on whether or not they received an apology. Results did not support previous findings that men and women differed in 
levels of forgiveness based on whether or not they received an apology. The current study also extended previous research by examining different types of apologies. Results indicated that women showed a faster recovery from the transgression when they received an elaborate apology than when they received a simple apology, and that men showed a faster recovery rate from the transgression than women when they received a simple apology. However, this effect was restricted to measures of HRV, suggesting that the effect was limited to recovery of the parasympathetic response, but not the sympathetic nervous system response. Although this study failed to replicate all previous findings by Whited et al. (2010), it provided some new information regarding how men and women respond differently to two different types of apology. Future research is needed to confirm the importance of measuring HRV parameters along with other cardiovascular parameters when examining the positive and potentially healthenhancing effects of apology. To the extent that these physiological effects facilitate the process of forgiveness, it appears that consideration of the victim's sex may be an important factor in predicting optimal methods for promoting forgiveness and benefiting from this positive psychology phenomenon. 


\section{References}

Anderson, J. C., Linden, W., \& Habra, M. E. (2006). Influence of apologies and trait hostility on recovery from anger. Journal of Behavioral Medicine, 29(4), 347-358.

Bachman, G. F., \& Guerrero, L. K. (2006). Forgiveness, apology, and communicative responses to hurtful events. Communication Reports, 19(1), 45-56. doi:10.1080/08934210600586357.

Boehm, J. K., Peterson, C., Kivimaki, M., \& Kubzansky, L. (2011). A prospective study of positive psychological well-being and coronary heart disease. Health Psychology, 30(3), 259-267. doi:10.1037/a0023124.

Brydon, L., Strike, P. C., Bhattacharyya, M. R., Whitehead, D. L., McEwan, J., Zachary, I., \& Steptoe, A. (2010). Hostility and physiological responses to laboratory stress in acute coronary syndrome patients. Journal of Psychosomatic Research, 68(2), 109-116. doi:10.1016/j.jpsychores.2009.06.007.

Carlisle, R. D., Tsang, J. A., Ahmad, N. Y., Worthington Jr, E. L., Witvliet, C. V., \& Wade, N. (2012). Do actions speak louder than words? Differential effects of apology and restitution on behavioral and self-report measures of forgiveness. The Journal of Positive Psychology, 7(4), 294-305.

Carroll, D., Ginty, A. T., Der, G., Hunt, K., Benzeval, M., \& Phillips, A. C. (2012). Increased blood pressure reactions to acute mental stress are associated with 16-year cardiovascular disease mortality. Psychophysiology, 49(10), 1444-1448. doi:10.1111/j.14698986.2012.01463.x.

Chatkoff, D. K., Maier, K. J., Javaid, J., Hammoud, M. K., \& Munkrishna, P. (2009). Dispositional hostility and gender differentially relate to cognitive appraisal, engagement, 
and cardiovascular reactivity across cognitive and emotional laboratory tasks. Personality and Individual Differences, 47(2), 122-126. doi: 10.1016/j.paid.2009.02.008.

Heart Disease Facts. (2014, February 19). Centers for Disease Control and Prevention.

Retrieved February 8, 2014, from http://www.cdc.gov/heartdisease/facts.htm.

Darby, B. W., \& Schlenker, B. R. (1982). Children's reactions to apologies. Journal of Personality and Social Psychology, 43(4), 742-753. doi:10.1037/0022-3514.43.4.742.

DuBois, C. M., Beach, S. R., Kashdan, T. B., Nyer, M. B., Park, E. R., Celano, C. M., \& Huffman, J. C. (2012). Positive psychological attributes and cardiac outcomes:

Associations, mechanisms, and interventions. Psychosomatics: Journal of Consultation and Liaison Psychiatry, 53(4), 303-318. doi:10.1016/j.psym.2012.04.004.

Frazer, N. L., Larkin, K. T., \& Goodie, J. L. (2002). Do behavioral responses mediate or moderate the relation between cardiovascular reactivity to stress and parental history of hypertension? Health Psychology, 21, 244-253.

Fredrickson, B. L., Mancuso, R. A., Branigan, C., \& Tugade, M. M. (2000). The undoing effect of positive emotions. Motivation and emotion, 24(4), 237-258.

Friedberg, J. P., Suchday, S., \& Srinivas, V. S. (2009). Relationship between forgiveness and psychological indices in cardiac patients. International Journal of Behavioral Medicine, 16(3), 205-211. doi:10.1007/s12529-008-9016-2.

Goldstein, H.S., Edelberg, R., Meier, C.F., \& Davis, L. (1988). Relationship of resting blood pressure and heart rate to experienced anger and expressed anger. Psychosomatic Medicine, 50, 321-329. 
Gonzales M. H., Pederson, J. H., Manning, D. J., \& Wetter, D. W. (1990). Pardon my gaffe: Effects of sex, status, and consequence severity on accounts. Journal of Personality and Social Psychology 58(4) 610-21.

Gross, J. J. (1998). Antecedent- and response-focused emotion regulation: Divergent consequences for experience, expression, and physiology. Journal of Personality and Social Psychology, 74, 224-237.

Gross, J. J, \& Levenson, R. W. (1993). Emotional suppression: Physiology, self-report, and expressive behavior, Journal of Personality and Social Psychology, 64, 970-986.

Guerrero, C., \& Palmero, F. (2010). Impact of defensive hostility in cardiovascular disease. Behavioral Medicine, 36(3), 77-84. doi:10.1080/08964280903521289.

Hart, K. E., \& Shapiro, D. A. (2002, August). Secular and spiritual forgiveness interventions for recovering alcoholics harboring grudges. Paper presented at the annual convention of the American Psychological Association, Chicago.

Hernandez, D. H., Larkin, K. T., \& Whited, M. C. (2009). Cardiovascular response to interpersonal provocation and mental arithmetic among high and low hostile young adult males. Applied Psychophysiology and Biofeedback, 34, 27-35.

Holt-Lunstad, J., Smith, T. W., \& Uchino, B. N. (2008). Can hostility interfere with the health benefits of giving and receiving social support? The impact of cynical hostility on cardiovascular reactivity during social support interactions among friends. Annals of Behavioral Medicine, 35(3), 319-330. doi: 10.1007/s12160-008-9041-z.

Holt, R. I. G., Phillips, D. I. W., Jameson, K. A., Cooper, C., Dennison, E. M., \& Peveler, R. C. (2013). The relationship between depression, anxiety and cardiovascular disease: Findings from the Hertfordshire Cohort Study. Journal of Affective Disorders, 150(1), 84-90. 
Retrieved from http://search.ebscohost.com/login.aspx?direct=true\&db=psyh\&AN=201331382-002\&site=ehost-live.

Honjo, K., Iso, H., Tsugane, S., Tamakoshi, A., Satoh, H., Tajima, K., . . Sobue, T. (2010). The effects of smoking and smoking cessation on mortality from cardiovascular disease among japanese: Pooled analysis of three large-scale cohort studies in japan. Tobacco Control: An International Journal, 19(1), 50-57. doi:10.1136/tc.2009.029751

Kamat, V. I., Jones, W. H., \& Row, K. L. (2006). Assessing Forgiveness as a Dimension of Personality. Individual Differences Research, 4(5), 322-330

Katcher, H. I., Legro, R. S., Kunselman, A. R., Gillies, P. J., Demers, L. M., Bagshaw, D. M., \& Kris-Etherton, P. M. (2008). The effects of a whole grain-enriched hypocaloric diet on cardiovascular disease risk factors in men and women with metabolic syndrome. American Journal of Clinical Nutrition, 87(1), 79-90.

Kinnier, R. T., Kernes, J. L., \& Dautheribes, T. M. (2000). A short list of universal moral values. Counseling and Values, 45(1), 4-16.

Krantz, D. S., Helmers, K. F., Bairey, C. N., \& Nebel, L. E. (1991). Cardiovascular reactivity and mental stress-induced myocardial ischemia in patients with coronary artery disease. Psychosomatic Medicine, 53(1), 1-12. Retrieved from http://search.ebscohost.com/login.aspx?direct=true\&db=psyh\&AN=1991-18955$\underline{001 \& \text { site }=\text { ehost-live }}$

Krantz, D. S., \& Manuck, S. B. (1984). Acute psychophysiologic reactivity and risk of cardiovascular disease: a review and methodologic critique. Psychological Bulletin, 96(3), 435-464. 
Kubo, K., Okanoya, K., \& Kawai, N. (2012). Apology isn't good enough: An apology suppresses an approach motivation but not the physiological and psychological anger. Plos One, 7(3) doi:10.1371/journal.pone.0033006

Lachman, M. E., \& Weaver, S. L. (1997). The Midlife Development Inventory (MIDI) personality scales: Scale construction and scoring. Waltham, MA: Brandeis University.

Larkin, K.T., Goulet, C., \& Cavanaugh, C. (2015). Forgiveness and physiological concomitants and outcomes. In L. Toussaint, E. Worthington, \& D. R. Williams (Eds.), Forgiveness and health: Scientific evidence and theories relating forgiveness to better health, (pp 61-76). New York, NY: Springer.

Larsen, B. A., Darby, R. S., Harris, C. R., Nelkin, D. K., Milam, P., \& Christenfeld, N. J. S. (2012). The immediate and delayed cardiovascular benefits of forgiving. Psychosomatic Medicine, 74(7), 745-750. doi:10.1097/PSY.0b013e31825fe96c

Lawler-Row, K. A., Hyatt-Edwards, L., Wuensch, K. L., \& Karremans., J. C. (2011). Forgiveness and health: The role of attachment. Personal Relationships, 18(2), 170-183. doi:10.1111/j.1475-6811.2010.01327.x

Lawler, K. A., Younger, J., Piferi, R. A., Billington, E., Jobe, R., Edmondson, K., \& Jones, W. H. (2003). A change of heart: Cardiovascular correlates of forgiveness in response to interpersonal conflict. Journal of Behavioral Medicine, 26, 373-393.

Lawler, K. A., Younger, J. W., Piferi, R. L., Jobe, R. L., Edmundson, K. A., \& Jones, W. H. (2005). The unique effects of forgiveness on health: An exploration of pathways. Journal of Behavioral Medicine, 28, 157-167. 
Low, C. A., Salomon, K., \& Matthews, K. A. (2009). Chronic life stress, cardiovascular reactivity, and subclinical cardiovascular disease in adolescents. Psychosomatic Medicine, 71(9), 927-931. doi:10.1097/PSY.0b013e3181ba18ed

Low, C. A., Thurston, R. C., \& Matthews, K. A. (2010). Psychosocial factors in the development of heart disease in women: Current research and future directions. Psychosomatic Medicine, 72(9), 842-854. doi:10.1097/PSY.0b013e3181f6934f

Lubin, B., Van Whitlock, R., Reddy, D., \& Petren, S. (2001). A comparison of the short and long forms of the Multiple Affect Adjective Check List-Revised (MAACL-R). Journal of Clinical Psychology, 57(3), 411-416.

Manuck, S.B., Kaplan, J.R., \& Clarkson, T.B. (1983). Behaviorally induced heart rate reactivity and atherosclerosis in cynomolgus monkeys. Psychosomatic Medicine, 45, 95-108.

Marler, M. R., Jacob, R. G., Lehoszky, J. P., \& Shapiro, A. P. (1988). The statistical analysis of treatment effects in 24-hour ambulatory blood pressure recordings. Statistics in Medicine, 7, 697-716.

Matthews, K. A., Katholi, C. R., McCreath, H., Whooley, M. A., Williams, D. R., Zhu, S., \& Markovitz, J. H. (2004). Blood pressure reactivity to psychological stress predicts hypertension in the CARDIA study. Circulation, 110(1), 74-78. doi:10.1161/01.CIR.0000133415.37578.E4

McCullough, M. E., Rachal, K. C., Sandage, S. J., Worthington Jr, E. L., Brown, S. W., \& Hight, T. L. (1998). Interpersonal forgiving in close relationships: II. Theoretical elaboration and measurement. Journal of Personality and Social Psychology, 75(6), 1586-1603.

McCullough, M. E., \& Witvliet, C. V. (2002). The psychology of forgiveness. Handbook of positive psychology, 2, 446-455. 
McCullough, M. E., Worthington Jr., E. L., \& Rachal, K. C. (1997). Interpersonal forgiving in close relationships. Journal of Personality and Social Psychology, 73(2), 321-336. doi:10.1037/0022-3514.73.2.321

McEwen, B. S., \& Stellar, E. (1993). Stress and the individual: Mechanisms leading to disease. Archives of Internal Medicine, 153(18), 2093-2101.

doi:10.1001/archinte.1993.00410180039004.

Miller, A., Worthington, E., \& McDaniel, M. (2008). Gender and forgiveness: A meta-analytic review and research agenda. Journal of Social \& Clinical Psychology. 27(8) 843-876.

Neumann, S. A., Maier, K. J., Brown, J. P., Giggey, P. P., Cooper, D. C., Synowski, S. J., ... \& Waldstein, S. R. (2011). Cardiovascular and psychological reactivity and recovery from harassment in a biracial sample of high and low hostile men and women. International Journal of Behavioral Medicine, 18(1), 52-64. doi: 10.1007/s12529-010-9110-0

Neumann, S. A., Waldstein, S. R., Sellers III, J. J., Thayer, J. F., \& Sorkin, J. D. (2004). Hostility and distraction have differential influences on cardiovascular recovery from anger recall in women. Health Psychology, 23(6), 631-640.

Ohbuchi, K., Kameda, M., \& Agarie, N. (1989). Apology as aggression control: Its role in mediating appraisal of and response to harm. Journal of Personality and Social Psychology, 56(2), 219-227.

Oreskovic, N. M., \& Goodman, E. (2013). Association of optimism with cardiometabolic risk in adolescents. Journal of Adolescent Health, 52(4), 407-412.

doi:10.1016/j.jadohealth.2012.09.011 
Roschk, H., \& Kaiser, S. (2013). The nature of an apology: An experimental study on how to apologize after a service failure. Marketing Letters, 24(3), 293-309. doi:10.1007/s11002012-9218-X

Rozanski, A., Blumenthal, J. A., \& Kaplan, J. (1999). Impact of psychological factors on the pathogenesis of cardiovascular disease and implications for therapy. Circulation, 99(16), 2192-2217.

Rozanski, A., \& Kubzansky, L. D. (2005). Psychologic functioning and physical health: A paradigm of flexibility. Psychosomatic Medicine, 67, S47-S53. doi:10.1097/01.psy.0000164253.69550.49

Rugulies, R. (2002). Depression as a predictor for coronary heart disease: a review and metaanalysis. American Journal of Preventive Medicine, 23(1), 51-61.

Schumann, K., \& Ross, M. (2010). Why women apologize more than men: Gender differences in thresholds for perceiving offensive behavior. Psychological Science, 21(11), 1649-1655. doi:10.1177/0956797610384150

Staiano, A. E., Harrington, D. M., Barreira, T. V., \& Katzmarzyk, P. T. (2013). Sitting time and cardiometabolic risk in us adults: associations by sex, race, socioeconomic status and activity level. Journal of Sports Medicine, 48(3), 213-219. doi: 10.1136/bjsports-2012091896

Strike, P. C., Magid, K., Brydon, L., Edwards, S., McEwan, J. R., \& Steptoe, A. (2004). Exaggerated platelet and hemodynamic reactivity to mental stress in men with coronary artery disease. Psychosomatic Medicine, 66(4), 492-500. doi:10.1097/01.psy.0000130492.03488.e7 
Struthers, C. W., Eaton, J., Santelli, A. G., Uchiyama, M., \& Shirvani, N. (2008). The effects of attributions of intent and apology on forgiveness: When saying sorry may not help the story. Journal of Experimental Social Psychology, 44(4), 983-992. doi:10.1016/j.jesp.2008.02.006

Tay, L., Tan, K., Diener, E., \& Gonzalez, E. (2013). Social relations, health behaviors, and health outcomes: A survey and synthesis. Applied Psychology: Health and Well-being, 5(1), 28-78. doi:10.1111/aphw.12000

Thomas, E. K., White, K., \& Sutton, G. W. (2008). Clergy apologies following abuse: What makes a difference? Exploring forgiveness, apology, responsibility-taking, gender, and restoration. Journal of Psychology and Christianity, 27(1), 16-29. Retrieved from http://search.ebscohost.com/login.aspx?direct=true\&db=psyh\&AN=2008-04098$\underline{002 \& \text { site }=\text { ehost-live }}$

Tindle, H. A., Chang, Y., Kuller, L. H., Manson, J. E., Robinson, J. G., Rosal, M. C., .. . Matthews, K. A. (2009). Optimism, cynical hostility, and incident coronary heart disease and mortality in the Women’s health initiative. Circulation, 120(8), 656-662. doi:10.1161/CIRCULATIONAHA.108.827642

Toussaint, L. L., Owen, A. D., \& Cheadle, A. (2012). Forgive to live: Forgiveness, health, and longevity. Journal of Behavioral Medicine, 35(4), 375-386. doi:10.1007/s10865-011-9362-4

Trapnell, P. D., \& Campbell, J. D. (1999). Private self-consciousness and the five-factor model of personality: Distinguishing rumination from reflection. Journal of personality and social psychology, 76(2), 284.

Treiber, F. A., Kamarck, T., Schneiderman, N., Sheffield, D., Kapuku, G., \& Taylor, T. (2003). Cardiovascular reactivity and development of preclinical and clinical disease states. Psychosomatic Medicine, 65(1), 46-62. Retrieved from 
http://search.ebscohost.com/login.aspx?direct=true\&db=psyh\&AN=2003-04875008\&site=ehost-live

Vella, E. J., \& Friedman, B. H. (2009). Hostility and anger in: cardiovascular reactivity and recovery to mental arithmetic stress. International Journal of Psychophysiology, 72(3), 253259. doi: 10.1016/j.ijpsycho.2009.01.003

Vogele, C., \& Steptoe, A. (1993). Anger inhibition and family history as modulators of cardiovascular responses to mental stress in adolescent boys. Journal of Psychosomatic Research, 37, 503-514.

Wade, N. G., \& Worthington, E. L. (2005). In search of a common core: A content analysis of interventions to promote forgiveness. Psychotherapy: Theory, Research, Practice, Training, 42(2), 160-177.

Waltman, M. A., Russell, D. C., Coyle, C. T., Enright, R. D., Holter, A. C., \& Swoboda, C. M. (2009). The effects of a forgiveness intervention on patients with coronary artery disease. Psychology \& Health, 24(1), 11-27. doi:10.1080/08870440801975127

Wang, H., Mittleman, M. A., Leineweber, C., \& Orth-Gomer, K. (2006). Depressive symptoms, social isolation, and progression of coronary artery atherosclerosis: The Stockholm female coronary angiography study. Psychotherapy and Psychosomatics, 75(2), 96-102. doi:10.1159/000090893

Webb, J. R., Hirsch, J. K., Visser, P. L., \& Brewer, K. G. (2013). Forgiveness and health: Assessing the mediating effect of health behavior, social support, and interpersonal functioning. Journal of Psychology: Interdisciplinary and Applied, 147(5), 391-414. doi:10.1080/00223980.2012.700964 
Whited, M. C., Wheat, A. L., \& Larkin, K. T. (2010). The influence of forgiveness and apology on cardiovascular reactivity and recovery in response to mental stress. Journal of Behavioral Medicine, 33(4), 293-304. doi:10.1007/s10865-010-9259-7

Witvliet, C., DeYoung, N., Hofelich, A. J., \& DeYoung, P. (2011). Compassionate reappraisal and emotion suppression as alternatives to offense-focused rumination: Implications for forgiveness and psychophysiological well-being. Journal of Positive Psychology, 6(4), 286299. doi:10.1080/17439760.2011.577091

Witvliet, C., Ludwig, T. E., \& Vander Laan, K. L. (2001). Granting forgiveness or harboring grudges: Implications for emotion, physiology, and health. Psychological Science, 12(2), 117-123.

Worthington, E. L., Sandage, S. J., \& Berry, J. W. (2000). Group interventions to promote forgiveness: What researchers and clinicians ought to know. In M. E. McCullough, K. I. Pargament, \& C. E. Thoresen (Eds.), Forgiveness: Theory, research, and practice (pp. 228253). New York: Guilford Press.

Wulsin, L. R., \& Singal, B. M. (2003). Do depressive symptoms increase the risk for the onset of coronary disease? A systematic quantitative review. Psychosomatic Medicine, 65(2), 201210.

Zuckerman, M., \& Lubin, B. (1985). Manual for the Multiple Affect Adjective Checklist. San Diego, CA: Educational and Industrial Testing Service. 
Table 1. Demographics

\begin{tabular}{|c|c|c|c|c|}
\hline & \multicolumn{2}{|c|}{ Men } & \multicolumn{2}{|c|}{ Women } \\
\hline & Mean (SE) & Count (\%) & Mean (SE) & Count (\%) \\
\hline Sex & & $36(46.7 \%)$ & & $41(53.3 \%)$ \\
\hline Age & $19.4(.24)$ & & $19.4(.16)$ & \\
\hline Race & & & & \\
\hline White & & 27 (75\%) & & $30(73.2 \%)$ \\
\hline Black & & $3(8.3 \%)$ & & $5(12.2 \%)$ \\
\hline Asian & & $5(13.9 \%)$ & & $3(7.3 \%)$ \\
\hline Native Am. & & 0 & & $1(2.4 \%)$ \\
\hline Mixed & & 0 & & $2(4.8 \%)$ \\
\hline Undisclosed & & $1(2.8 \%)$ & & 0 \\
\hline $\begin{array}{c}\text { Fam. History of } \\
\text { Hypertension }\end{array}$ & & & & \\
\hline Yes & & $14(38.8 \%)$ & & $14(34.1 \%)$ \\
\hline No & & $22(61.2 \%)$ & & 27 (65.9\%) \\
\hline BMI & $24.9(.54)$ & & $23.6(.54)$ & \\
\hline Resting SBP (mm & & & & \\
\hline Hg) & $114.8(1.54)$ & & $108.9(1.2)$ & \\
\hline Resting DBP (mm & & & & \\
\hline Hg) & $61.0(1.36)$ & & $65.0(1.46)$ & \\
\hline Resting MAP (mm & & & & \\
\hline Hg) & $79.4(1.25)$ & & 79.7 (1.04) & \\
\hline Resting HR & $74.9(1.6)$ & & $77.8(1.46)$ & \\
\hline Resting SDNN & $68.5(3.8)$ & & $63.1(3.18)$ & \\
\hline RRQ & $40.8(1.5)$ & & $42.3(1.0)$ & \\
\hline FPI & $123.0(2.3)$ & & $122.4(2.1)$ & \\
\hline Extraversion & $1.8(.1)$ & & $2.1(.1)$ & \\
\hline Agreeableness & $1.8(.1)$ & & $2.5(.2)$ & \\
\hline Neuroticism & $2.8(.1)$ & & $2.7(.1)$ & \\
\hline Conscientiousness & $1.8(.1)$ & & $2.5(.2)$ & \\
\hline Agency & $2.4(.1)$ & & $2.3(.1)$ & \\
\hline Openness to & & & & \\
\hline Experience & $2.0(.1)$ & & $2.5(.1)$ & \\
\hline
\end{tabular}


Table 2. Means and standard deviations for cardiovascular parameters during rest, task, and recovery

\begin{tabular}{|c|c|c|c|c|c|c|}
\hline & \multicolumn{3}{|c|}{ Men } & \multicolumn{3}{|c|}{ Women } \\
\hline & No Apo. & Simple Apo. & $\begin{array}{c}\text { Elaborate } \\
\text { Apo. }\end{array}$ & No Apo. & Simple Apo & $\begin{array}{l}\text { Elaborate } \\
\text { Apo. }\end{array}$ \\
\hline SBP Rest & 114.8 (8.9) & $117.0(6.8)$ & $113.1(11.4)$ & 106.2 (8.9) & $112.9(4.2)$ & $108.2(6.9)$ \\
\hline SBP Task & $133.0(14.5)$ & $136.1(10.6)$ & 138.1 (9.7) & $121.9(10.2)$ & $131.1(12.9)$ & $123.1(8.0)$ \\
\hline SBP Reco. & $120.8(9.8)$ & $122.5(7.7)$ & 123.0 (11.8) & 114.5 (9.9) & $120.6(5.8)$ & $115.6(5.1)$ \\
\hline DBP Rest & $60.3(8.3)$ & $61.2(8.2)$ & $61.2(8.6)$ & $65.6(8.4)$ & $66.2(7.3)$ & $63.1(12.5)$ \\
\hline DBP Task & 74.2 (12.9) & $69.8(13.4)$ & 73.6 (9.7) & 69.5 (10.4) & $68.3(7.7)$ & $72.0(10.5)$ \\
\hline DBP Reco. & $62.4(7.1)$ & $61.8(5.5)$ & $64.1(8.3)$ & $67.0(6.2)$ & $69.2(8.0)$ & $65.5(10.4)$ \\
\hline MAP Rest & $80.0(8.5)$ & 79.8 (6.8) & 78.5 (7.7) & 79.2 (5.7) & 81.7 (5.5) & 78.1 (8.8) \\
\hline MAP Task & $93.8(8.1)$ & 91.9 (11.4) & $95.1(8.3)$ & $87.0(6.0)$ & $89.2(6.2)$ & $89.0(8.2)$ \\
\hline MAP Reco. & $81.9(4.5)$ & 82.0 (4.9) & 83.7 (7.8) & $82.8(5.1)$ & $86.4(6.0)$ & 82.2 (7.7) \\
\hline HR Rest & $68.6(6.3)$ & 77.5 (9.3) & 75.7 (10.7) & $75.3(8.4)$ & 79.8 (11.3) & 77.1 (7.6) \\
\hline HR Task & 80.9 (9.7) & 88.9 (11.3) & $91.1(12.2)$ & $90.5(10.2)$ & $96.1(15.1)$ & $92.8(9.2)$ \\
\hline HR Reco. & $70.9(4.5)$ & $78.4(10.2)$ & $78.6(9.1)$ & 75.7 (7.3) & $81.4(11.9)$ & $77.8(7.5)$ \\
\hline HF-HRV Rest & $6.8(.96)$ & $6.5(1.0)$ & $6.4(1.1)$ & $6.8(.75)$ & $6.5(1.2)$ & $6.7(.62)$ \\
\hline HF-HRV Task & $6.4(.92)$ & $6.3(.87)$ & $6.2(.94)$ & $6.2(.83)$ & $5.2(1.6)$ & $6.2(.73)$ \\
\hline HF-HRV Reco. & $6.5(.70)$ & $6.6(1.1)$ & $6.3(.97)$ & $6.7(.90)$ & $6.1(1.2)$ & $6.7(.65)$ \\
\hline
\end{tabular}


Table 3. Means and standard errors for measures of affect at each phase of experiment Men Women

\begin{tabular}{lcccccc}
\hline & No Apo. & $\begin{array}{c}\text { Simple } \\
\text { Apo. }\end{array}$ & $\begin{array}{c}\text { Elaborate } \\
\text { Apo. }\end{array}$ & No Apo. & $\begin{array}{c}\text { Simple } \\
\text { Apo }\end{array}$ & $\begin{array}{l}\text { Elaborate } \\
\text { Apo. }\end{array}$ \\
\hline MAACL-R Rest & & & & & & \\
Negative Affect & $1.6(.6)$ & $3.8(1.1)$ & $1.1(.4)$ & $1.8(.4)$ & $1.2(.4)$ & $2.1(.5)$ \\
Positive Affect & $8.5(1.8)$ & $3.3(.69)$ & $5.7(1.0)$ & $4.6(.8)$ & $9.5(1.5)$ & $2.3(.5)$ \\
\hline MAACL-R Task & & & & & & \\
Negative Affect & $7.0(1.4)$ & $11.4(1.5)$ & $8.2(1.1)$ & $8.7(1.3)$ & $12.2(1.9)$ & $8.1(.9)$ \\
Positive Affect & $3.7(1.5)$ & $1.3(.4)$ & $.8(.2)$ & $.6(.2)$ & $.8(.3)$ & $.7(.4)$ \\
\hline MAACL-R Recovery & & & & & & \\
Negative Affect & $1.8(.8)$ & $3.0(1.1)$ & $2.5(.9)$ & $2.6(.6)$ & $3.2(1.2)$ & $2.8(.6)$ \\
Positive Affect & $6.5(1.6)$ & $3.2(.7)$ & $4.3(1.3)$ & $2.8(.54)$ & $4.3(1.1)$ & $2.3(.4)$ \\
\hline
\end{tabular}

Note: Means and standard errors presented here are not transformed. All statistical analyses for affect were performed on transformed data. 
Table 4. Means and standard errors for responses to the post-experimental questionnaire

$$
\text { Men Women }
$$

\begin{tabular}{|c|c|c|c|c|c|c|}
\hline & $\begin{array}{c}\text { No } \\
\text { Apology }\end{array}$ & $\begin{array}{c}\text { Simple } \\
\text { Apology }\end{array}$ & $\begin{array}{l}\text { Elaborate } \\
\text { Apology }\end{array}$ & $\begin{array}{c}\text { No } \\
\text { Apology }\end{array}$ & $\begin{array}{c}\text { Simple } \\
\text { Apology }\end{array}$ & $\begin{array}{l}\text { Elaborate } \\
\text { Apology }\end{array}$ \\
\hline $\begin{array}{l}\text { In comparison with other } \\
\text { stressful tasks that you } \\
\text { encounter in daily life, the } \\
\text { math challenge was more } \\
\text { stressful. }\end{array}$ & $3.7(.43)$ & $3.8(.22)$ & $3.6(.27)$ & $4.2(.27)$ & $4.1(.21)$ & $3.4(.31)$ \\
\hline $\begin{array}{l}\text { I often encounter tasks like } \\
\text { the math challenge that I } \\
\text { completed today. } *\end{array}$ & $2.9(.41)$ & $2.3(.22)$ & $2.9(.29)$ & $3.2(.32)$ & $1.8(.22)$ & $2.0(.33)$ \\
\hline $\begin{array}{l}\text { The experimenter was very } \\
\text { effective at helping you to } \\
\text { achieve your best } \\
\text { performance. * }\end{array}$ & $3.4(.56)$ & $3.2(.27)$ & $3.3(.34)$ & 4.5 (.19) & $2.9(.38)$ & $1.7(.26)$ \\
\hline $\begin{array}{l}\text { The experimenter enjoyed } \\
\text { giving you feedback while } \\
\text { you did the math task. }\end{array}$ & $2.8(.25)$ & $3.3(.25)$ & $3.1(.22)$ & $2.3(.33)$ & $2.8(.22)$ & $2.5(.19)$ \\
\hline $\begin{array}{l}\text { The experimenter was } \\
\text { supportive during the } \\
\text { completion of the math } \\
\text { task. ** }\end{array}$ & $2.8(.51)$ & $2.4(.43)$ & $2.1(.33)$ & $3.8(.21)$ & $2.4(.37)$ & $1.6(.23)$ \\
\hline $\begin{array}{l}\text { The experimenter was } \\
\text { supportive after the math } \\
\text { task was completed. }\end{array}$ & $3.6(.16)$ & $4.3(.22)$ & $4.3(.16)$ & $3.4(.19)$ & $4.3(.17)$ & $3.9(.31)$ \\
\hline $\begin{array}{l}\text { The experimenter intended } \\
\text { to be rude.** }\end{array}$ & $3.5(.43)$ & $4.2(.27)$ & $4.1(.23)$ & $1.9(.23)$ & $4.6(.18)$ & $4.1(.34)$ \\
\hline $\begin{array}{l}\text { The experimenter was very } \\
\text { rude. }\end{array}$ & $2.9(.41)$ & $3.2(.32)$ & $3.5(.27)$ & $2.4(.36)$ & $3.3(.31)$ & $3.2(.3)$ \\
\hline $\begin{array}{l}\text { I forgave the experimenter } \\
\text { for interrupting me during } \\
\text { the task.** }\end{array}$ & $4.1(.28)$ & $4.5(.19)$ & $4.6(.17)$ & $2.9(.17)$ & $4.8(.10)$ & $4.7(.14)$ \\
\hline $\begin{array}{l}\text { I am annoyed with the } \\
\text { experimenter for what } \\
\text { he/she did during the task. }\end{array}$ & $2.2(.33)$ & $2.3(.33)$ & $2.2(.3)$ & $1.8(.29)$ & $1.7(.21)$ & $2.8(.35)$ \\
\hline $\begin{array}{l}\text { The apology that you } \\
\text { received was very sincere. }\end{array}$ & N/A & $3.8(.21)$ & $4.5(.17)$ & N/A & $4.3(.21)$ & $4.5(.23)$ \\
\hline $\begin{array}{l}\text { I have received an apology } \\
\text { similar to the one that I } \\
\text { received from the } \\
\text { experimenter. }\end{array}$ & N/A & $3.8(.21)$ & $3.9(.23)$ & N/A & $3.8(.21)$ & $4.2(.27)$ \\
\hline
\end{tabular}


The apology you received

from the experimenter was

very similar to apologies

that your typically receive.

N/A $\quad 3.4(.19)$

$3.4(.23)$

N/A

$3.8(.20)$

(.27)

*Main effect for Sex

**Main effect for Apology 
Figure 1: Systolic blood pressure of men and women during rest, task period, and recovery.

Men

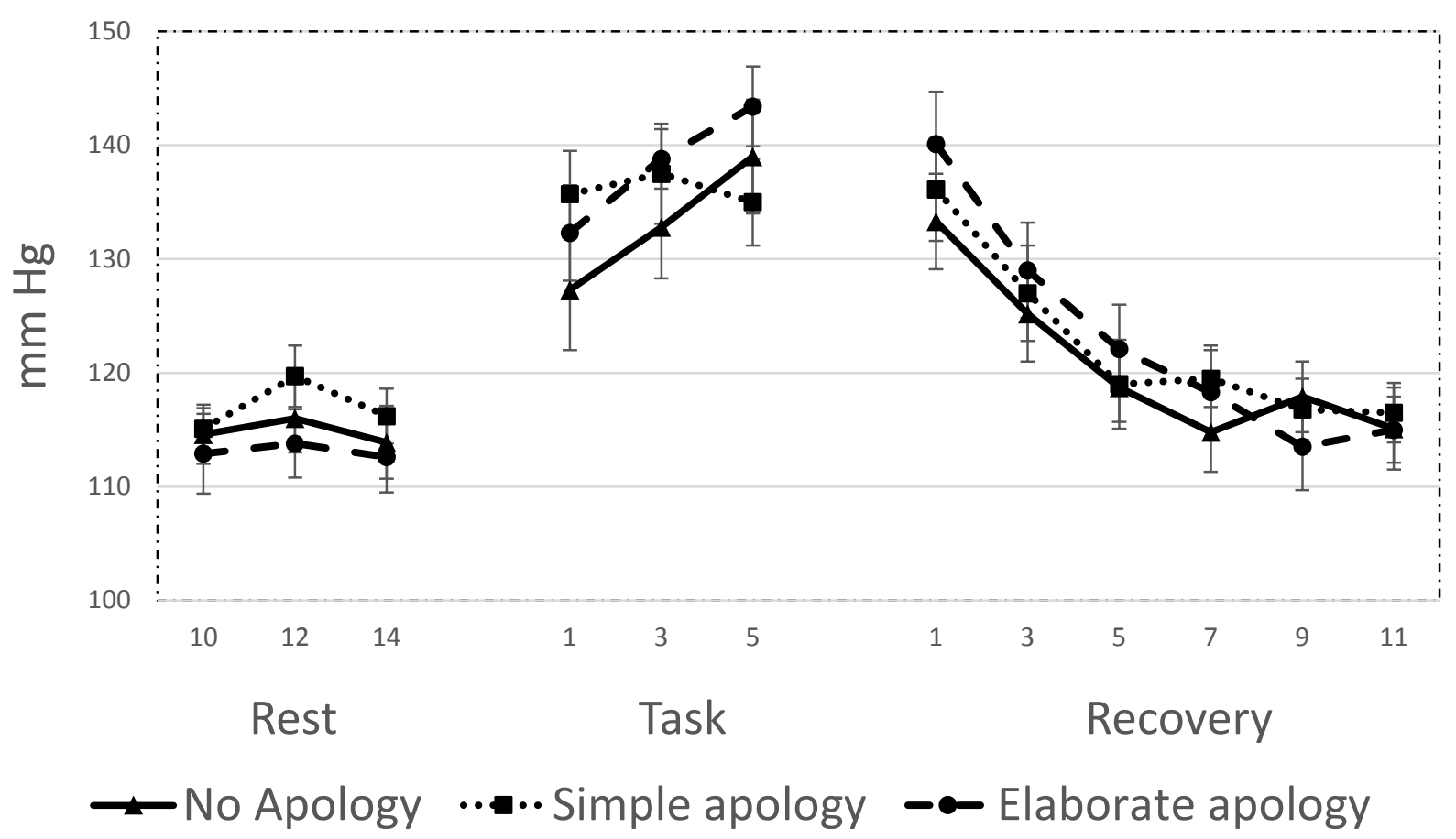

Women

150
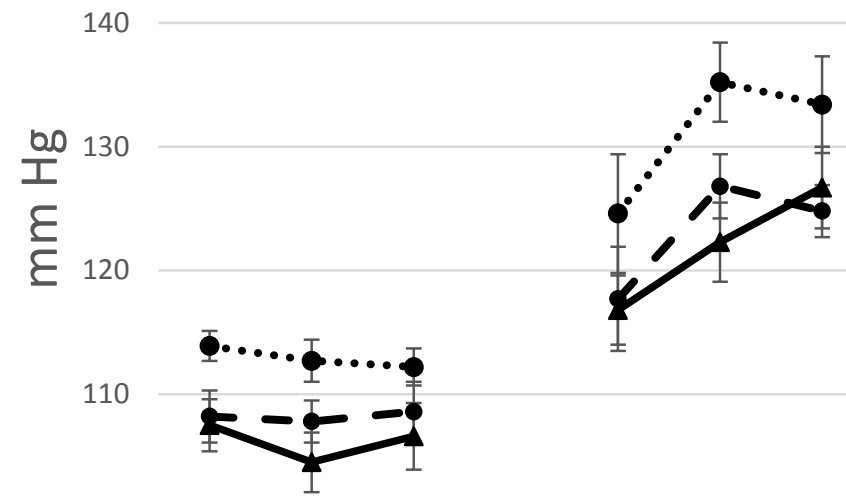

100

$\begin{array}{lll}10 & 12 & 14\end{array}$

135

13

Rest

Task

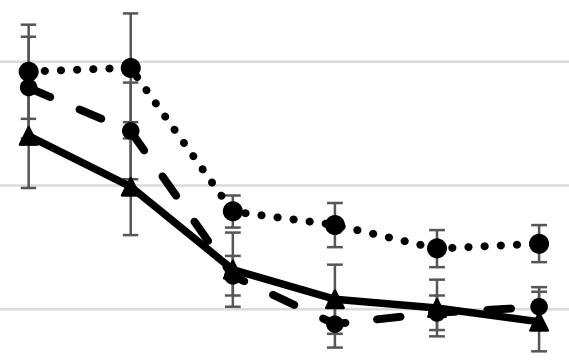

—No Apology ..•.. Simple Apology -•-Elaborate Apology 
Figure 2: Diastolic Blood Pressure of men and women during rest, task period, and recovery.

Men

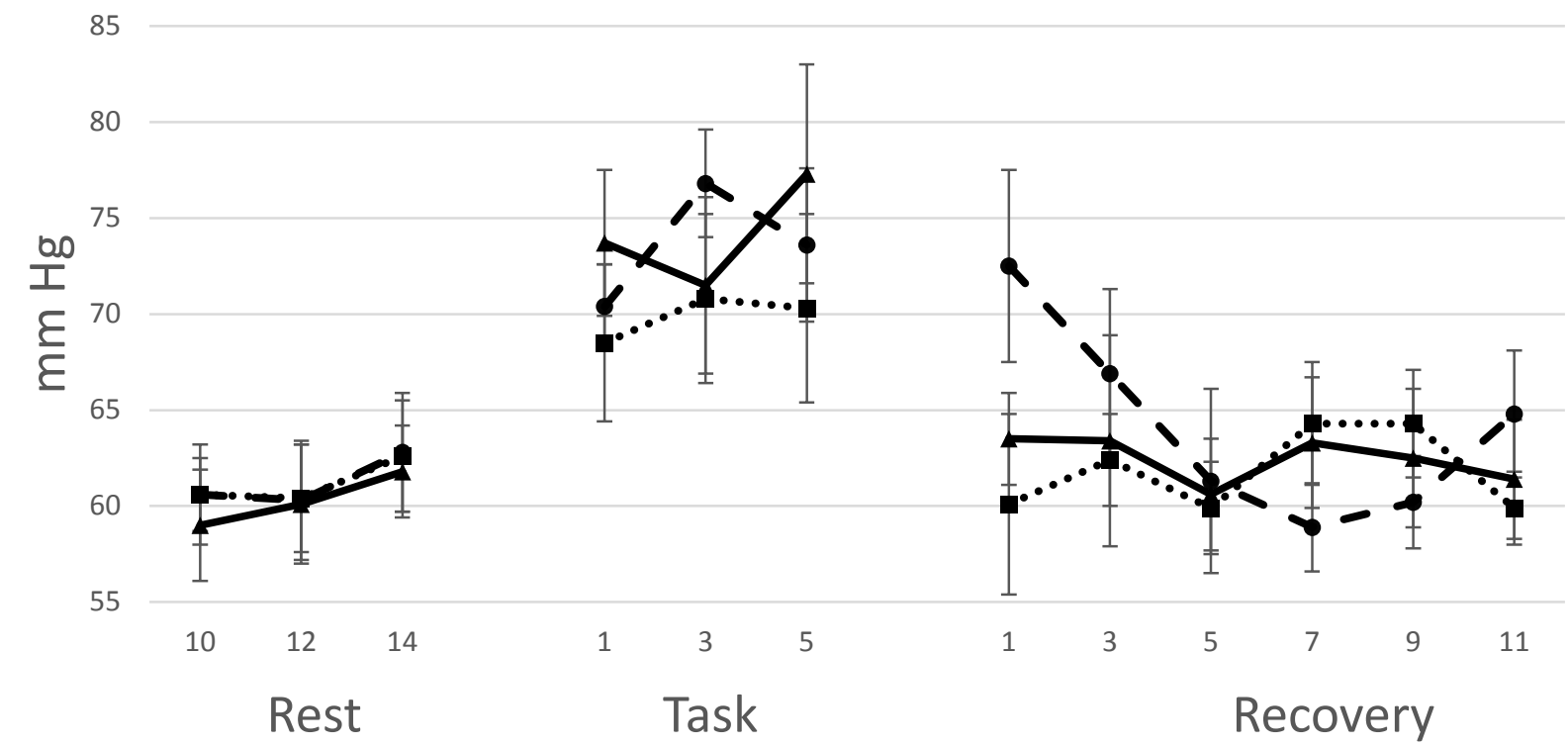

—No Apology ….. Simple apology -o- Elaborate apology

Women

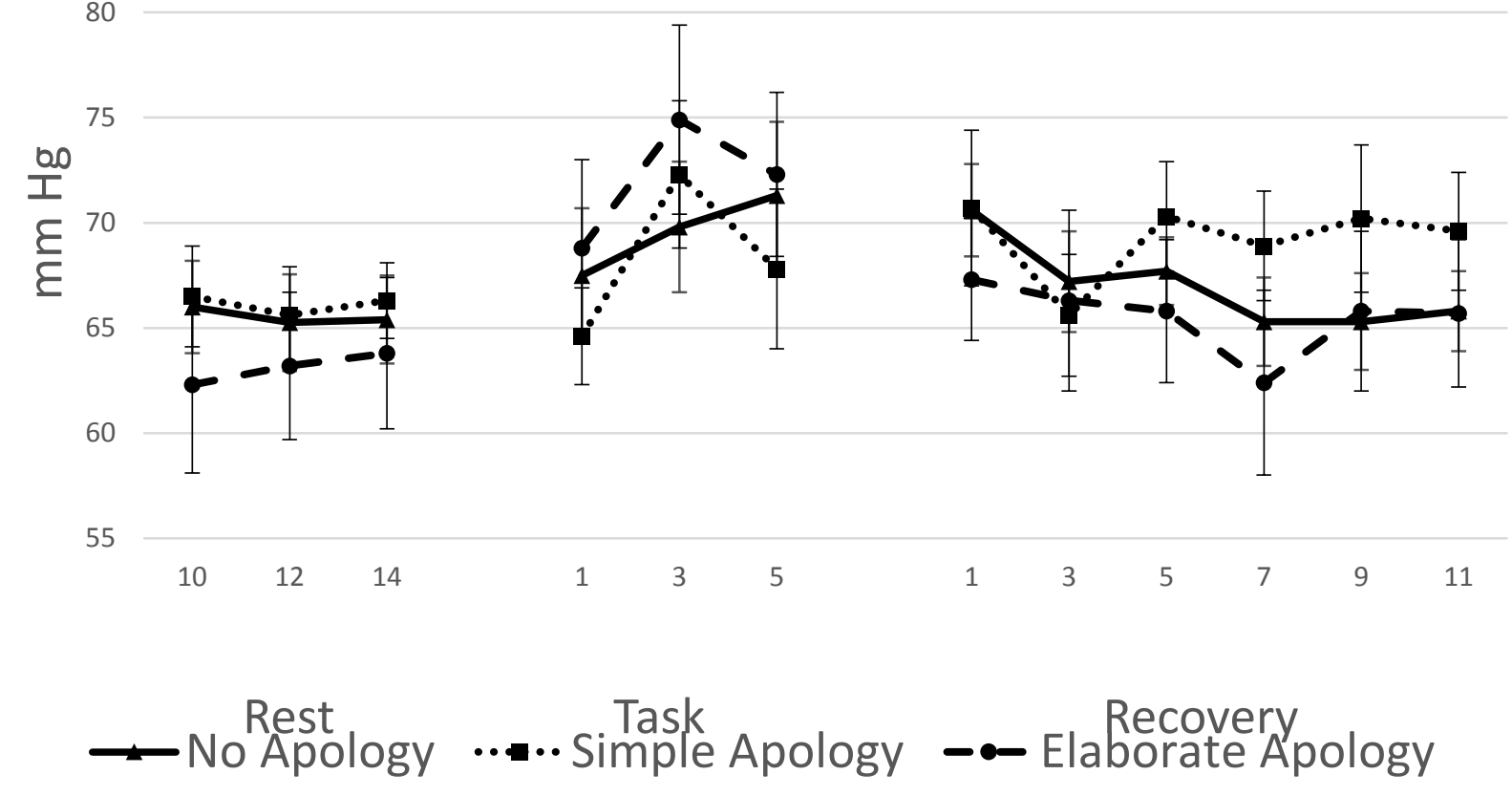


Figure 3: Mean Arterial Pressure of men and women during rest, task period, and recovery.

Men

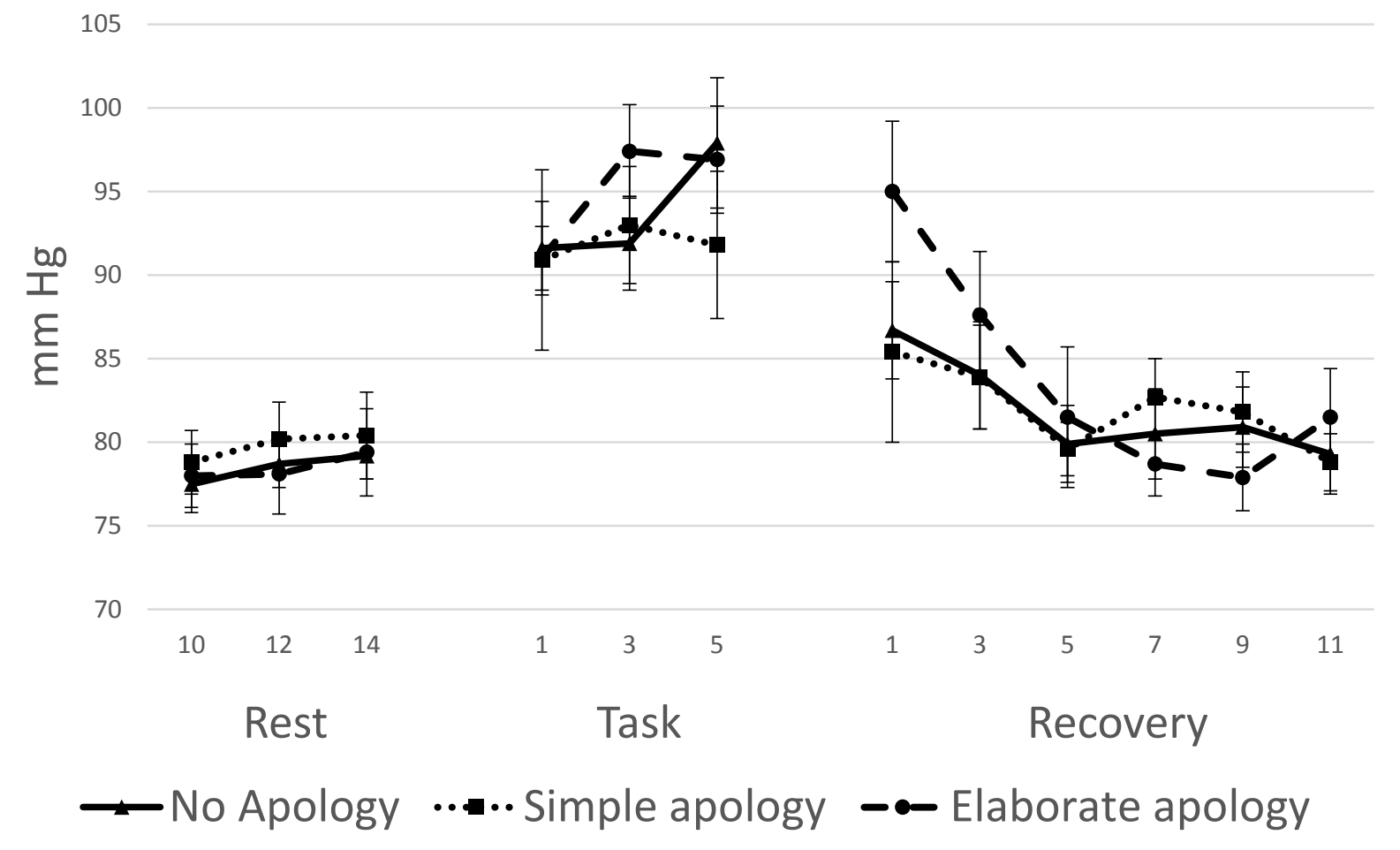

Women

\section{5}

\section{0}
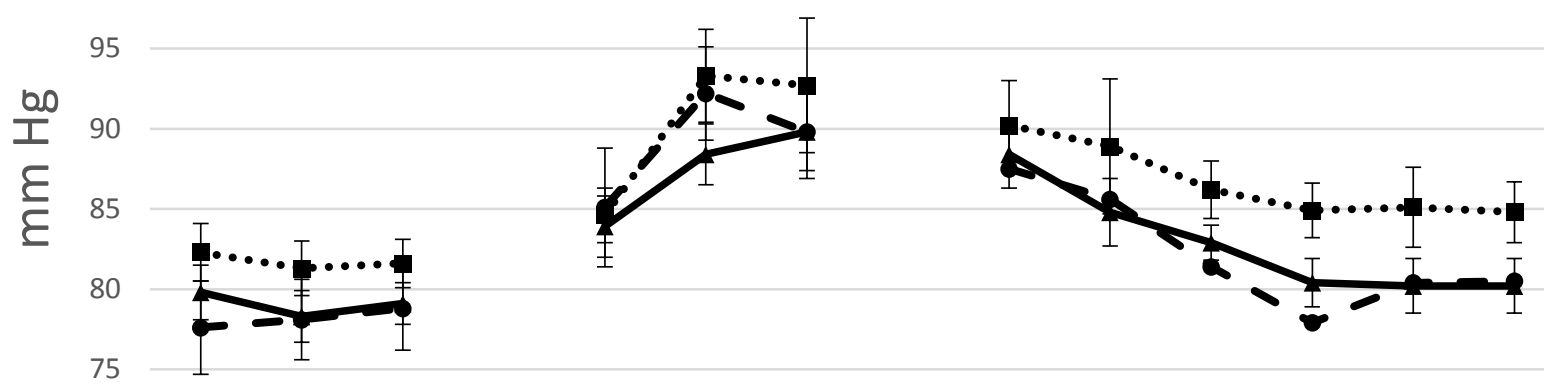

70

$\begin{array}{lll}10 & 12 & 14\end{array}$

135

1

3

7

11

Rest

Task

Recovery

—No Apology ...... Simple Apology -•- Elaborate Apology 
Figure 4: Heart Rate of men and women during rest, task period, and recovery.

Men

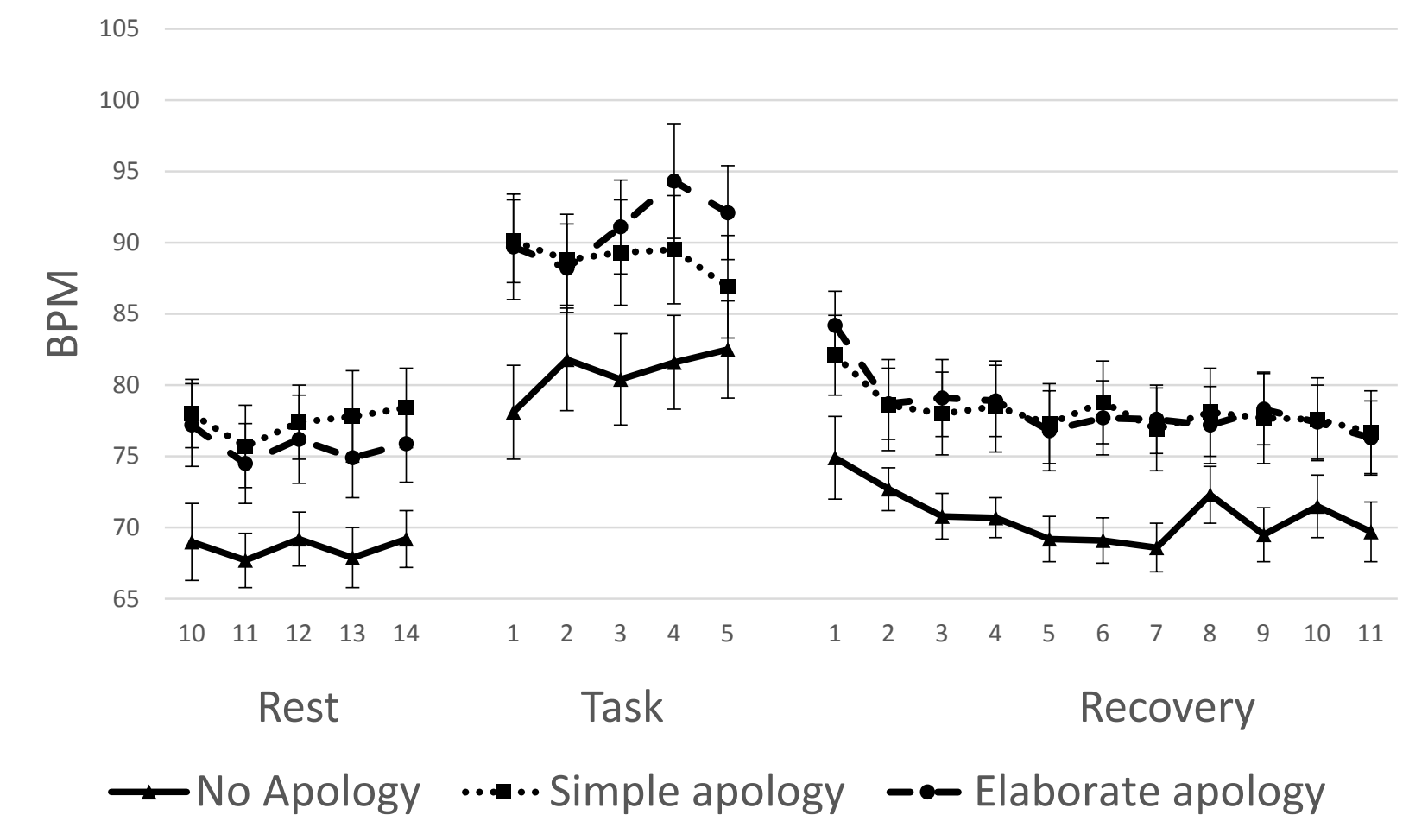

Women

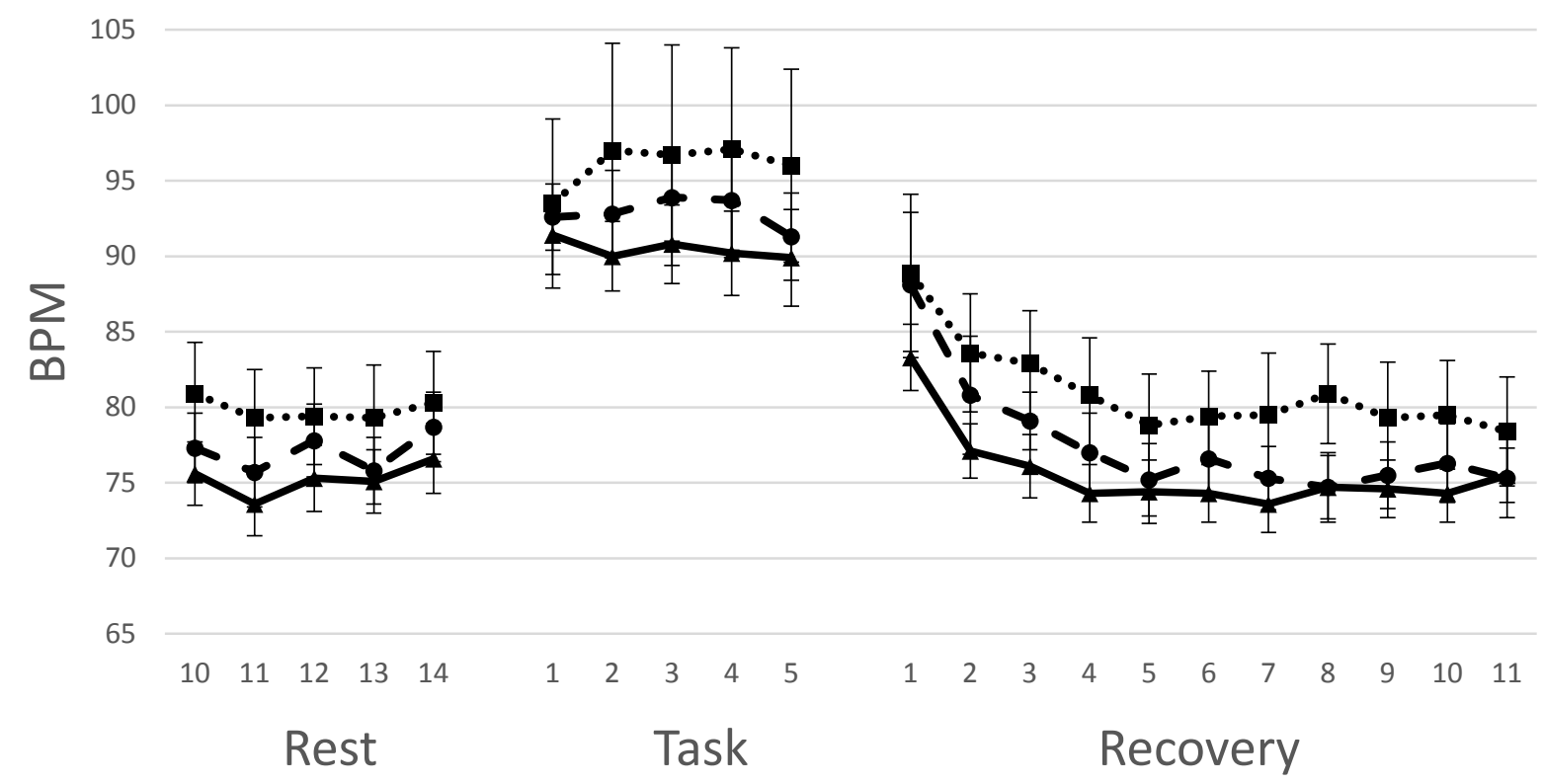

—No Apology ….. Simple apology - - Elaborate apology 
Figure 5: HF-HRV of men and women during rest, task period, and recovery.

Men

\section{Males HF-HRV}

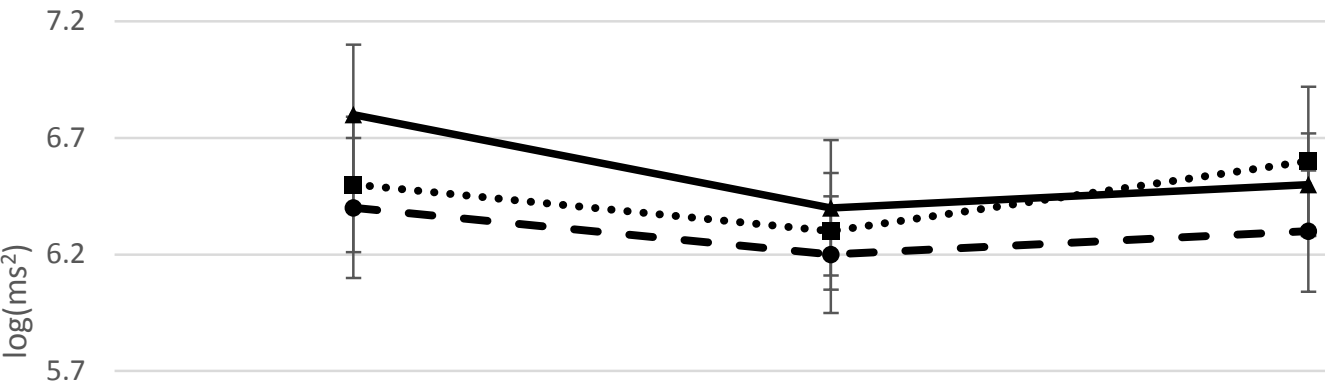

5.2

4.7

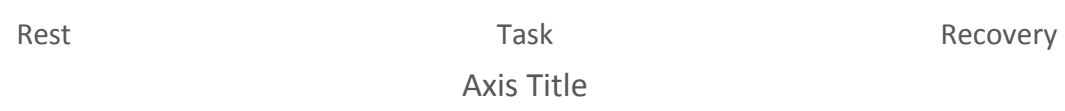

- No Apology .... Simple apology - Elaborate apology

Women

\section{Females HF-HRV}

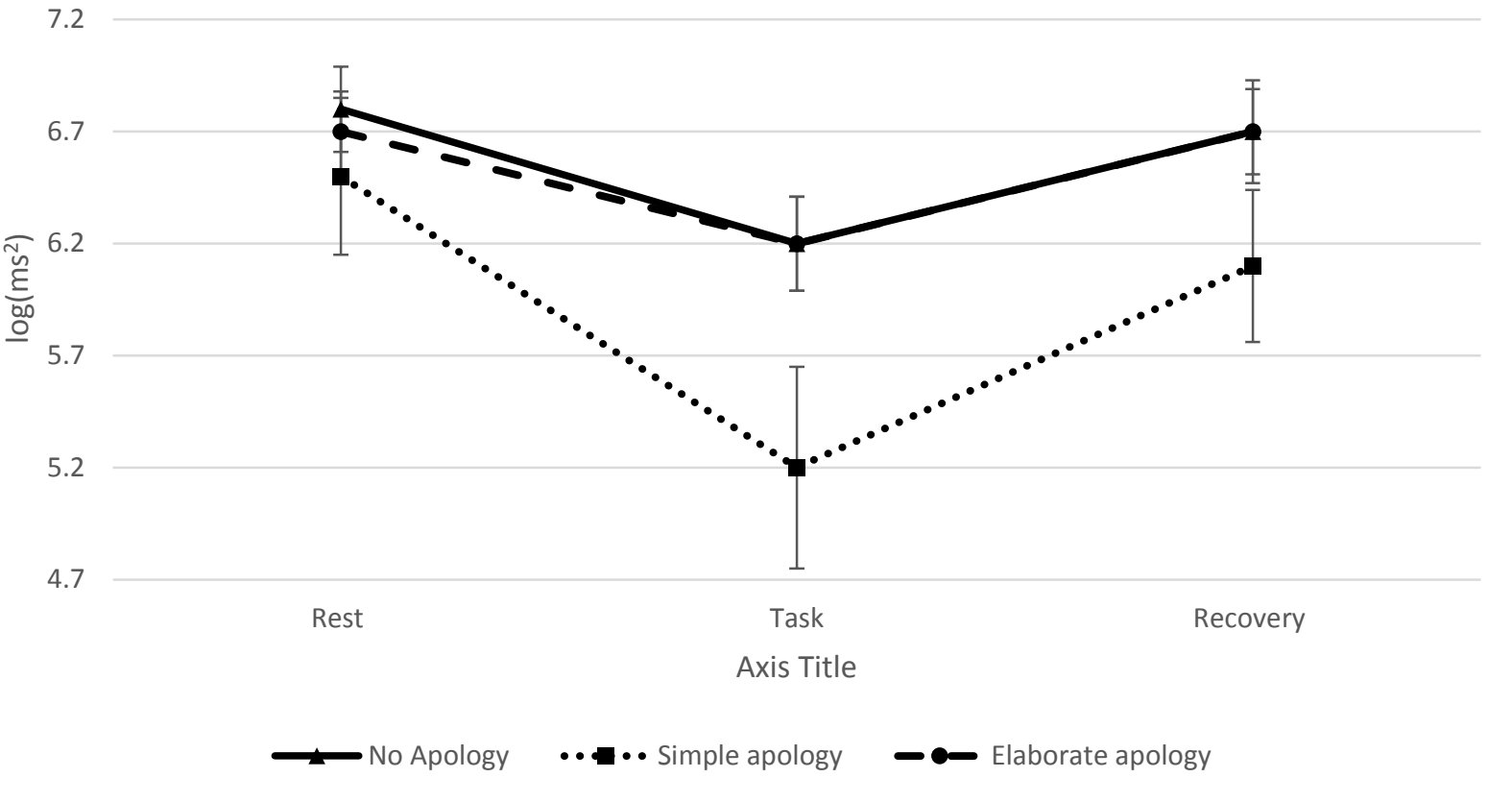


Figure 6: Sex X Apology Group interaction for HF-HRV

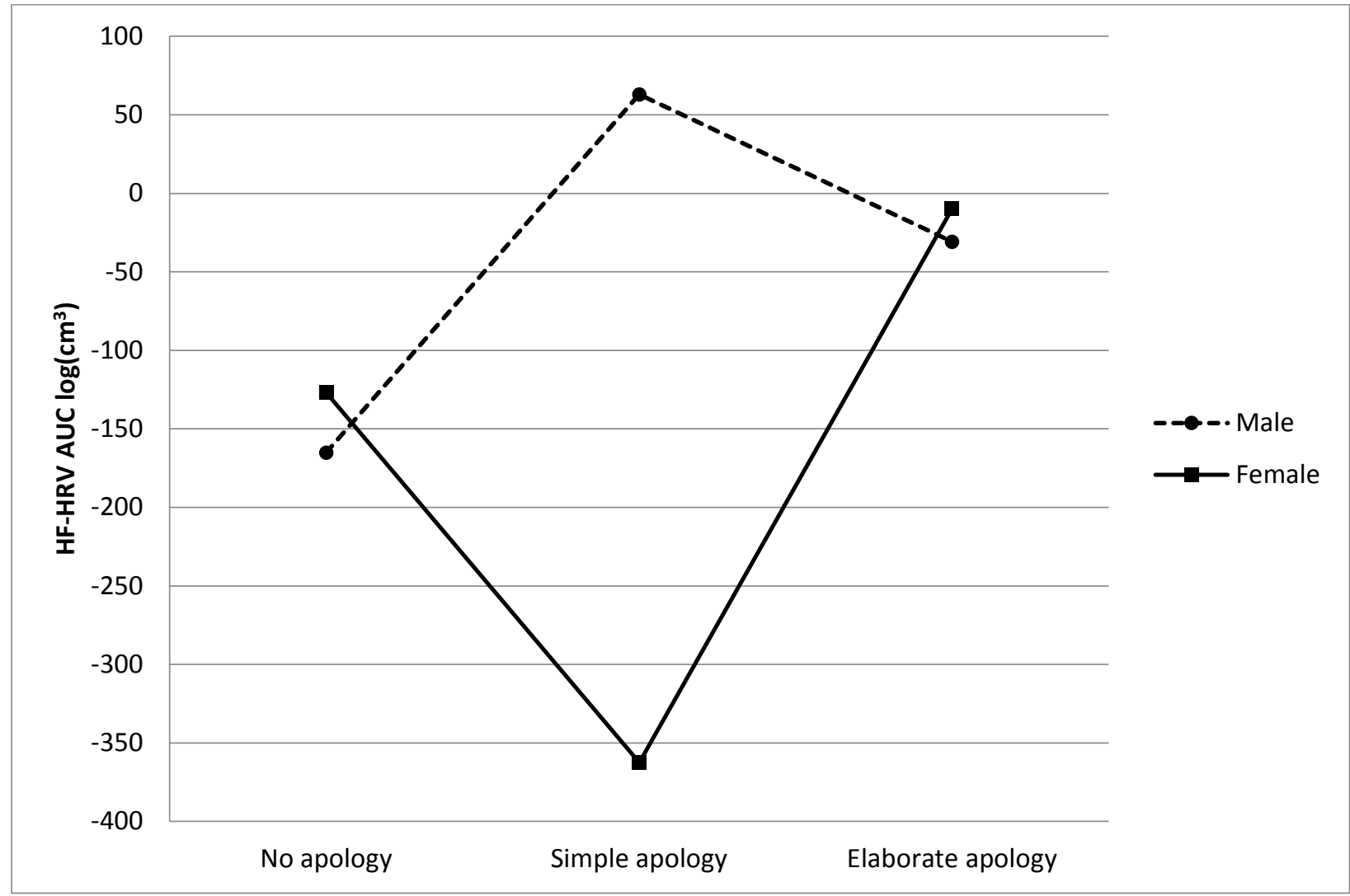




\section{Appendix A}

Demographics Questionnaire

Participant \#:

Height(in.):

Please provide your email address so that we can contact you for part 2 of the study:

\section{Your Information:}

Your age

Your sex
- Male
○ Female

Are you Hispanic, Latino, or of Spanish origin?

o No, not of Hispanic, Latino, or Spanish origin

o Yes, Mexican, Mexican Am., Chicano

o Yes, Puerto Rican

o Yes, Cuban

o Yes, another Hispanic, Latino, or Spanish origin (please indicate)

Your race- check all that apply

○ White

- Black, African Am., or Negro

- American Indian or Alaska Native

- Asian Indian

○ Chinese
Date:

Weight(lbs): 

- Filipino
o Japanese
o Korean
o Vietnamese
o Native Hawaiian
o Guamanian or Chamorro

o Samoan

o Other Pacific Islander (please indicate)

o Other Asian (please indicate)

o Other race (please indicate)

Indicate the highest level of education you have completed:
$\circ$ High school
○ 1 year college
○ 2 years college
○ 3 years college
○ 4 or more years college

Please describe any cardiovascular related illness that you may have, including high blood pressure:

Please list any other medical or psychiatric problems that you have: 
Please list any major surgeries and medical, or psychiatric illnesses you have had in the past.

Females: Are you currently pregnant?

$\circ$ Yes

$\circ$ No

Females: Are you currently on birth control (contraceptives).

○ Yes

$\circ$ No

What type of birth control are you taking?

Please list any drugs (legal or otherwise) that you are currently taking including; birth control (contraceptives), heart medications, cold or allergy medications, over the counter medications, asthma medications, Beta-Blockers (i.e. Inderal, Tenormin), psychoactive drugs (i.e. Adderall, Xanax, Haldol, Lithium, Prozac), or diet pills.

Do you currently smoke cigarettes (within the last month)?
○ Yes
○ No 
Do you currently use smokeless tobacco (within the past month)?
o Yes
○ No

How often do you drink alcohol?

$$
\begin{aligned}
& \text { o never } \\
& \text { o infrequently (a few drinks per year) } \\
& \text { o occasionally (1-2 drinks per month) } \\
& \text { } \text { weekly (1-3 drinks per week) } \\
& \text { o weekly (3-6 drinks per week) } \\
& \circ \text { daily (7-14 drinks per week) } \\
& \circ \text { daily (more than } 14 \text { drinks per week) }
\end{aligned}
$$

How many cups of caffeinated coffee, tea, or soda do you have per day?

$$
\begin{aligned}
& \circ \text { none } \\
& \text { 1-2 cups per day } \\
& \text { 3-4 cups per day } \\
& \text { 5-6 cups per day } \\
& \text { 7-8 cups per day } \\
& \circ \text { greater than eight cups per day }
\end{aligned}
$$

How many times per week do you engage in aerobic physical activity?

$$
\begin{aligned}
& \text { never } \\
& \text { 1-2 times } \\
& \text { 3-6 times } \\
& \circ 7 \text { or more times }
\end{aligned}
$$


For how long do you typically exercise on each occasion?

$$
\begin{aligned}
& \text { 5-10 minutes } \\
& \text { o 10-15 minutes } \\
& \text { o 15-30 minutes } \\
& \text { o 30-60 minutes } \\
& \text { o more than } 60 \text { minutes }
\end{aligned}
$$

\section{Family Information:}

Imagine a ladder that represents where people stand in the United States.

At the top of the ladder are the people who are the best off - those who have the most money, the most education, and the most respected jobs. At the bottom are the people who are the worst off - who have the least money, least education, and the least respected jobs or no job. The higher up you are on this ladder, the closer you are to the people at the very top; the lower you are, the closer you are to the people at the very bottom.

On which rung of the ladder (1 being the lowest rung and 10 being the highest rung) would you place your family?
$1 .$. $2 \ldots \ldots . . .3$
$4 \ldots \ldots . . .5$ $6 \ldots \ldots . . . .7$
$7 \ldots \ldots . . .8$
$9 \ldots \ldots \ldots . .10$

Is your father currently living?

$$
\begin{aligned}
& \circ \text { yes } \\
& \circ \text { no }
\end{aligned}
$$

Approximately how old is your father?

Did/does your father have high blood pressure (hypertension)?

$$
\circ \text { yes }
$$


$\circ$ no

How certain are you that he did, or did not, have high blood pressure (hypertension)?

○ Absolutely (100\%) certain

○ Almost (75\%) certain

$\circ$ Not sure at all $(25 \%)$

$\circ$ No information by which to judge $(0 \%)$

Did/does your father have any heart problems such as angina (chest pains), a heart attack, or coronary heart disease?

$$
\begin{aligned}
& \circ \text { yes } \\
& \circ \text { no }
\end{aligned}
$$

If yes, please specify if you are able:

How certain are you that he did, or did not, have a heart problem as indicated above?

$$
\begin{aligned}
& \circ \text { Absolutely }(100 \%) \text { certain } \\
& \circ \text { Almost }(75 \%) \text { certain } \\
& \text { Not sure at all }(25 \%) \\
& \circ \text { No information by which to judge }(0 \%)
\end{aligned}
$$

Is your mother currently living?

$$
\begin{aligned}
& \circ \text { yes } \\
& \circ \text { no }
\end{aligned}
$$

Approximately how old is your mother?

Did/does your mother have high blood pressure (hypertension)?

$$
\circ \text { yes }
$$


$\circ$ no

How certain are you that she did, or did not, have high blood pressure (hypertension)?

○ Absolutely (100\%) certain

○ Almost (75\%) certain

$\circ$ Not sure at all $(25 \%)$

$\circ$ No information by which to judge $(0 \%)$

Did/does your mother have any heart problems such as angina (chest pains), a heart attack, or coronary heart disease?

$$
\begin{aligned}
& \circ \text { yes } \\
& \circ \text { no }
\end{aligned}
$$

If yes, please specify if you are able:

How certain are you that she did, or did not, have a heart problem as indicated above?
○ Absolutely (100\%) certain
$\circ$ Almost (75\%) certain
$\circ$ Not sure at all $(25 \%)$
$\circ$ No information by which to judge $(0 \%)$ 


\section{Appendix B \\ Post Experimental Questionnaire}

\section{Instructions:}

For each of the statements located below, please indicate your level of agreement or disagreement by circling one of the scale categories to the right of each statement. Use the scale as shown below:

\section{Strongly Disagree Disagree Neutral Agree Strongly Agree 1 2 3 4 5}

1. In comparison with other stressful tasks that you encounter in daily life, the math challenge was more stressful........................................ $12 \quad 2 \quad 3 \quad 4 \quad 5$

2. I often encounter tasks like the math challenge that I completed today. $\begin{array}{lllll}.1 & 2 & 3 & 4 & 5\end{array}$

3. The experimenter was instructed to give you feedback to help you perform on the math challenge. The experimenter was very effective at helping you to achieve your best performance....................................... $2 \begin{array}{llll}2 & 3 & 4 & 5\end{array}$

4. The experimenter enjoyed giving you feedback while you did the math task. $\begin{array}{lllll}\ldots 1 & 2 & 3 & 4 & 5\end{array}$

5. The experimenter was supportive during the completion of the math task. $\begin{array}{lllll}1 & 2 & 3 & 4 & 5\end{array}$

6. The experimenter was supportive after the math task was completed. $\begin{array}{llll}2 & 3 & 4 & 5\end{array}$

7. The experimenter intended to be rude. $\begin{array}{llll}2 & 3 & 4 & 5\end{array}$

8. The experimenter was very rude..................................... $\quad 2 \quad 3 \quad 4 \quad 5$

9. I forgave the experimenter for interrupting me during the task................ $2 \quad 2 \quad 3 \quad 4 \quad 5$

10. I am annoyed with the experimenter for what he/she did during the task.

11. The apology that you received was very sincere. . $.1 \quad 2 \quad 3 \quad 4 \quad 5$

12. I have received an apology similar to the one that I received from the experimenter. $\begin{array}{lllll}.1 & 2 & 3 & 4 & 5\end{array}$

13. The apology you received from the experimenter was very similar to apologies you typically receive.

(Note: If the participant was in the "no apology group, the final three items on the post-experimental questionnaire were omitted.) 


\section{Appendix C}

Approved Informed Consent Agreement

\section{W. WestVurginiaUniversity.}

Human Research Protocol

Only Minimal Risk Consent Form

(With HIPAA)

\section{Only Minimal Risk \\ Consent Information and HIPAA Form}

Principal Investigator

Department

Protocol Number

Study Title

Co-Investigator(s)
Kevin T. Larkin

Psychology

1407351087

Physiology of Mental Stress: An Investigation into Potential Sex Differences

Daniel J. Stephenson

\section{Contact Persons}

In the event you experience any side effects or injury related to this research, you should contact Dr. Larkin at (304) 2931700. If you have any questions, concerns, or complaints about this research, you can contact Dr. Larkin at (304) 2931700 or Daniel Stephenson via email at djstephenson@mix.wvu.edu.

For information regarding your rights as a research subject, to discuss problems, concerns, or suggestions related to the research, to obtain information or offer input about the research, contact the Office of Research Compliance at (304) 293-7073.

In addition if you would like to discuss problems, concerns, have suggestions related to research, or would like to offer input about the research, contact the Office of Research Integrity and Compliance at 304-293-7073.

\section{Introduction}

You, have been asked to participate in this research study, which has been explained to you

by . This study is being conducted by Daniel

Stephenson in the Department of Psychology at West Virginia University as his Master's thesis project. It is anticipated that 78 students will participate in this study.

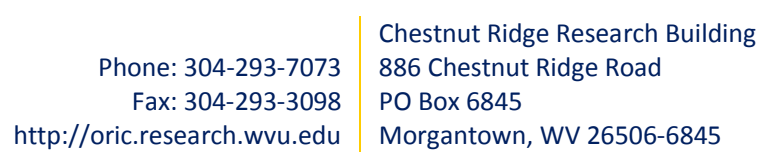

Chestnut Ridge Research Building

Morgantown, WV 26506-6845
P a g e | 77

Initials__ Subject's




\section{Purpose(s) of the Study}

The purpose of this study is to examine changes in heart rate and blood pressure during a mental stress task among males and females.

\section{Description of Procedures}

This study involves performing a mental arithmetic task while your blood pressure and heart rate are measured, and will take approximately 1 hour for you to complete. You will be asked to fill out questionnaires regarding your health and your current mood throughout the study. You do not have to answer all the questions. You will have the opportunity to see the questionnaire before signing this consent form. In order to obtain heart rate data, you will be required to wear a Polar heart rate monitor, which consists of a strap placed on your abdomen just below your chest.

After filling out a brief questionnaire, the experimenter will leave the room in order to allow you to connect the Polar heart rate monitor. The experimenter will then connect the blood pressure cuff to your arm. Next you will be instructed to rest for a 15 minute period, following which you will fill out a questionnaire about your mood. You will then perform a 5-minute mental arithmetic task, followed by filling out another questionnaire about your mood. You will then sit quietly for 11 minutes, and finally, you will fill out another questionnaire about your mood and experience during the experiment. Blood pressure will be taken frequently throughout the duration of the experiment.

\section{Discomforts}

There are no known or expected risks from participating in this study, except for the mild frustration associated with answering the questions, discomfort resulting from having your blood pressure measured, and potential discomfort while performing the mental arithmetic task. If sustained discomfort does occur, you may be referred to the student health clinic and/or student counseling center.

\section{Alternatives}

You do not have to participate in this study.

\section{Benefits}

You may not receive any direct benefit from this study. The knowledge gained from this study may eventually benefit others.

\section{Financial Considerations}

You will be paid $\$ 10$ cash at the completion of the laboratory portion of this study. You must provide your name and address to receive payment. If you withdraw before the end of the study, no additional payments will be made.

You will also earn extra credit for participating in the laboratory portion of this study. Other options are available for earning the same extra credit.

Phone: 304-293-7073

Fax: 304-293-3098

http://oric.research.wvu.edu
Chestnut Ridge Research Building

886 Chestnut Ridge Road

PO Box 6845

Morgantown, WV 26506-6845
P a g e | 78

Subject's 


\section{Confidentiality}

Data will be de-identified immediately by assigning a participant number to your data. Your name will not be connected to the data we obtain from you in any way. Any information about you that is obtained as a result of your participation in this research will be kept as confidential as legally possible. Your research records may be subpoenaed by court order or federal regulatory authorities without your additional consent.

In any publications that result from this research, neither your name nor any information from which you might be identified will be published.

\section{HIPAA}

We know that information about you and your health is private. We are dedicated to protecting the privacy of that information. All information obtained from you will be de-identified through the assignment of a participant ID number. Your de-identified individual health information will not be shared with anyone outside of the research staff for this project.

You can decide to sign or not to sign this authorization section. However, if you choose not to sign this authorization, you will not be able to take part in the research study.

\section{Persons/Organizations Providing the Information}

Participant

\section{Persons/Organizations Receiving the Information}

- The research site(s) carrying out this study. This includes WVU. It also includes each site's research staff.

- The members and staff of any Institutional Review Board (IRB) that oversees this research study.

- West Virginia University Office of Research Compliance and Office of Sponsored Programs.

\section{The Following Information Will Be Used}

Information about you that is created or collected during the study such as: health history, demographic data, blood pressure and heart rate recordings.

\section{The Information is Being Disclosed for the Following Reasons}

- $\quad$ Review of your data for quality assurance purposes

- $\quad$ Publication of study results (without identifying you)

\section{You May Cancel this Authorization at Any Time by Writing to the Principal Investigator}

Kevin Larkin

klarkin@wvu.edu

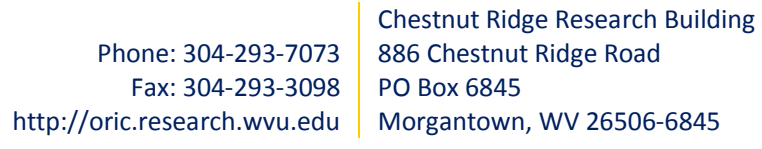

Chestnut Ridge Research Building

PO Box 6845

Morgantown, WV 26506-6845
P a g e | 79

Subject's 
If you cancel this authorization, any information that was collected already for this study cannot be withdrawn. Once information is disclosed, according to this authorization, the recipient may re-disclose it and then the information may no longer be protected by federal regulations.

You have a right to see and make copies of your medical records. You will not be able to see or copy your records related to the study until the sponsor has completed all work related to the study. At that time you may ask to see the study doctor's files related to your participation in the study and have the study doctor correct any information about you that is wrong.

This authorization will expire at the end of the study unless you cancel it before that time.

\section{Voluntary Participation}

Participation in this study is voluntary. You are free to withdraw your consent to participate in this study at any time.

Refusal to participate or withdrawal will not affect your class standing or grades, and will involve no penalty to you.

Refusal to participate or withdrawal will not affect your future care, or your employee status at West Virginia University.

In the event new information becomes available that may affect your willingness to participate in this study, this information will be given to you so that you can make an informed decision about whether or not to continue your participation.

You have been given the opportunity to ask questions about the research, and you have received answers concerning areas you did not understand.

Upon signing this form, you will receive a copy.

I willingly consent to participate in this research.

\section{Signatures}

Signature of Subject

Printed Name $\quad$ Date Time

The participant has had the opportunity to have questions addressed. The participant willingly agrees to be in the study.

Signature of Investigator or Co-Investigator

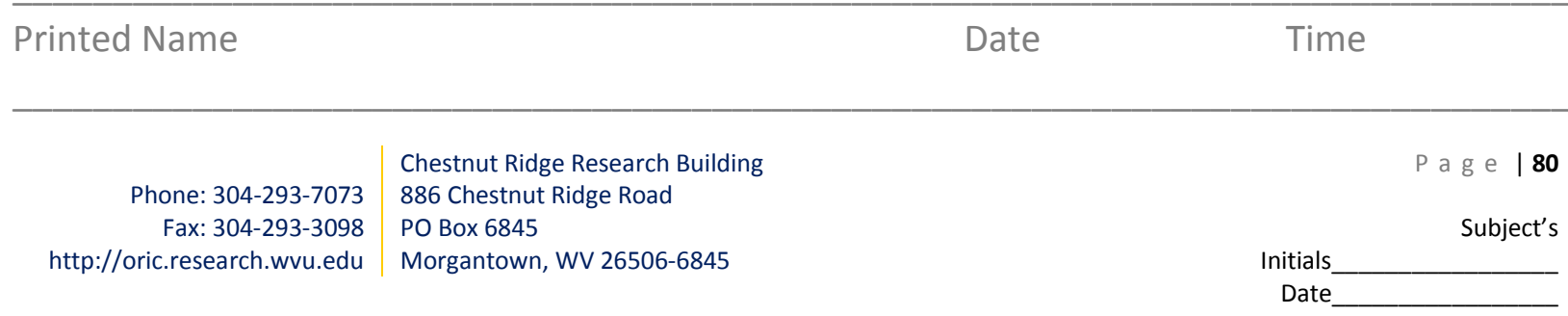




\section{Appendix D}

Simple Apology Pilot Testing

Prior to conducting the main study, pilot testing was conducted to determine which apology to use for the simple apology manipulation. Three simple apologies that were similar to the long apology in content, but shorter in length, were created. The apologies were:

(1) "Sorry that I was rude. It is part of the experiment,"

(2) “As part of the experiment I was rude to you. I am sorry,” and

(3) "Part of this experiment required me to be rude to you. I am sorry."

The three simple apologies were shown to ten graduate students in the Department of Psychology, and they were asked to rate each apology across four domains: (1) how genuine it was, (2) how awkward it seemed, (3) how realistic it seemed, and (4) how likely it was that they might receive an apology similar to the one being presented. Finally, graduate students were asked to rank the three apologies in terms of overall quality from best to worst.

The majority of graduate students ranked Apology 2, “As part of the experiment I was rude to you. I am sorry,” as the overall best apology. This apology was also rated as the most genuine and most realistic of the three and was therefore chosen to be used in the experiment. 


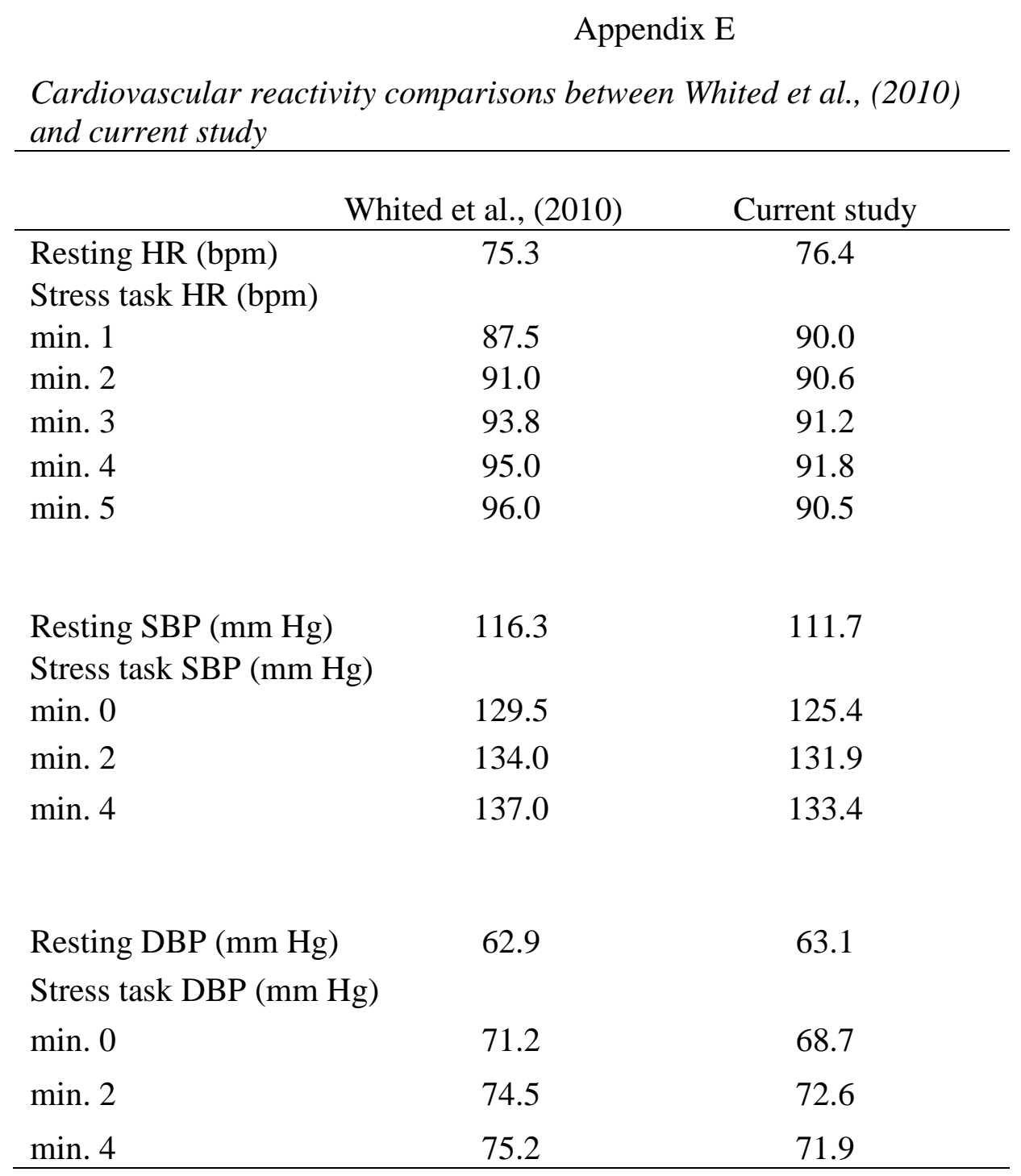

